\title{
Time-Fractal Modulation-Possible Modulation Effects in Human Therapy
}

\author{
Andras Szasz \\ Department of Biotechnics, Szent Istvan University, Budaors, Hungary \\ Email: biotech@gek.szie.hu
}

How to cite this paper: Szasz, A. (2022) Time-Fractal Modulation-Possible Modulation Effects in Human Therapy. Open Journal of Biophysics, 12, 38-87.

https://doi.org/10.4236/ojbiphy.2022.121003

Received: October 12, 2021

Accepted: January 11, 2022

Published: January 14, 2022

Copyright $\odot 2022$ by author(s) and Scientific Research Publishing Inc. This work is licensed under the Creative Commons Attribution International License (CC BY 4.0).

http://creativecommons.org/licenses/by/4.0/

\begin{abstract}
The malignant processes deviate from the healthy homeostatic control, and various "tricks" enable malignant cells to avoid the healthy regulation. Consequently, the malignant structures miss the apoptosis and proliferate without restriction, and without the formation of communication networks in the newly formed cells. The modulation supports the homeostatic control to rearrange the health regulation processes in various ways. The modulation acts with stochastic processes, using stochastic resonances for molecular excitations, supporting the regulative enzymatic processes. The number of stochastic resonant frequencies is as many as the number of enzymatic reactions. The malignant cells differ structurally and dynamically in their connections and interactions from their healthy host tissues. The radiofrequency carrier is modulated with an appropriate time-fractal (1/f) noise to select the autonomic cancer-cells, destroy them, or force the precancerous, semi-individual cells to participate in the networking connections. The modulation in this way limits the cellular autonomy of malignant cells and boosts the healthy control. The resonant energy triggers apoptotic processes and helps immunogenic actions deliver extracellular genetic information for antigen-presentation. The modulation is applied in clinical practice. The therapy (modulated electro-hyperthermia, mEHT) is intensively used in oncology in complementary applications and for palliative stages, and occasionally even as a monotherapy.
\end{abstract}

\section{Keywords}

Pink-Noise, Homeostasis, Amplitude-Modulation, Cellular-Communication, Antigen-Presentation, Stochastic Resonances, Resonance Frequencies, Cellular Networking

\section{Introduction}

Healthy homeostasis controls the dynamic balance in the organism, ensuring the 
harmony of complex micro- and macro-interactions. Cancer destroys this harmony. The modulation goal is to find and force the malignant cells into apoptosis and to restore the healthy synchrony between cells and their communication.

The malignant processes are driven by the unicellular behavior and the individualism of the involved cells. The result is the breakdown of the integrity of the multicellular organization (which normally has a healthy networking structure). Cells with autonomy behavior have potential to better adapt to environmental changes. The transformation from the organized multicellular structure seen in healthy tissues to the structure seen in tumors is driven by the primitive transcriptional programs active in malignant cells [1]. The reorganization of the tumors structure supports the unicellular behavior and autonomy of the malignant cells, promoting the survival of the "colony" of malignant cells [2]. In an attempt to correct the abnormality, the healthy host initiates processes, such as angiogenesis, nerve healing, and numerous other supports, which instead provide essential conditions for the development of the malignancy. This regulation follows the general homeostatic control of the body. From the time that the malignancy appears in the tissue, cancer becomes a systemic disease. The dynamic control mechanisms of the healthy host are not able to repair the malignant lesion due to various reasons: genetic aberrations [3], mitochondrial dysfunction [4], and other intra- [5] and extracellular [6] hallmarks of cancer. Additional challenges which the host must face are the permanent uncontrolled stress on the system exerted by the malignancy [7], the recognition of the lesion as an unhealed wound [8], inflammation [9], and the blocking of apoptotic activity in malignant cells [10].

Cancer is an organizing (networking) disease, where the cells abandon the cooperative advantages [11]. The application of a tool that can help the homeostasis mechanisms to correct the cellular disorder of the malignant lesion and induce apoptosis, could allow for the cancerous cells, which are acting autonomously, to return to a healthy network by forcing cooperative harmony. Our objective is to show the possible effects of the modulated radiofrequency (RF) carrier, and its preclinical and clinical applications, in order to achieve this goal.

\section{Methods-The Modulationphenomena}

The concept of modulation applied in physiology is centered on the stochastic dynamics (time-dependent events) in the biosystems. The chosen frequency spectrum is devoted to promoting healthy controls and intended to suppress cancerous processes. The carrier frequency is in the radiofrequency (RF) range which delivers an audio range $(<20 \mathrm{kHz})$ to the target. This method is well known and intensively applied by the various telecommunication networks (radio, TV, phone, GPS, etc.) to transfer information between the source and the distant targets.

The masking of the carrier can be achieved using different features of the RF wave, like its amplitude, frequency, or phase. The amplitude modulation was 
historically the first form of modulation, and it is the easiest to decode the delivered information (demodulation). The resulting shape of the signal follows the shape of modulation (Figure 1); mirroring the modulation signal at both the positive and negative side of the delivery. This amplitude modulation is very vulnerable to environmental noises and absorbents.

\subsection{Why Modulation and not Direct Excitations?}

The question naturally arises: while the advantages of frequency modulation include better stability over distance, less vulnerability to interferences, better selectivity, why then do we not propose applying directly the modulation frequencies in order to transmit information in biological systems without carrier frequency?

The challenge is to deliver the low frequency to the body and the selected places. The low frequencies are blocked by the heterogenic isolating (capacitive) factors in the application. The adipose tissue in the layer at the skin, the various membranes, and isolation compartments block the low-frequency current because their electric impedance inversely depends on the frequency. This resistivity becomes too high in low frequencies, and no deep targeting of structures is possible. In order to overcome the adipose layer, invasive application could be introduced, but other isolations remain.

The proper solution for the direct effect would be the invasive application of low-frequency, electrodes in the tumor itself, where the low-frequency effect of isolators is negligible. However, the inserted electrodes develop a layer on the surface of electrodes in the tumor, which produces a complex impedance effect (Warburg impedance, $Z_{W}$ ) [12] and has an inverse-square-root dependence on the frequency $(f)$. In a case of planar-electrode and sinusoidal supply, the Warburg impedance is [13]:

$$
Z_{W}(f)=A \frac{(1-i)}{\sqrt{f}}
$$

where $A$ is a constant and $i=\sqrt{-1}$. To avoid the Warburg impedance, a high

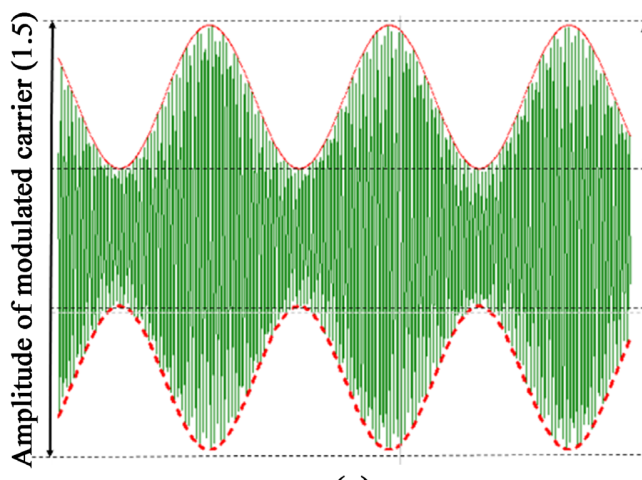

(a)

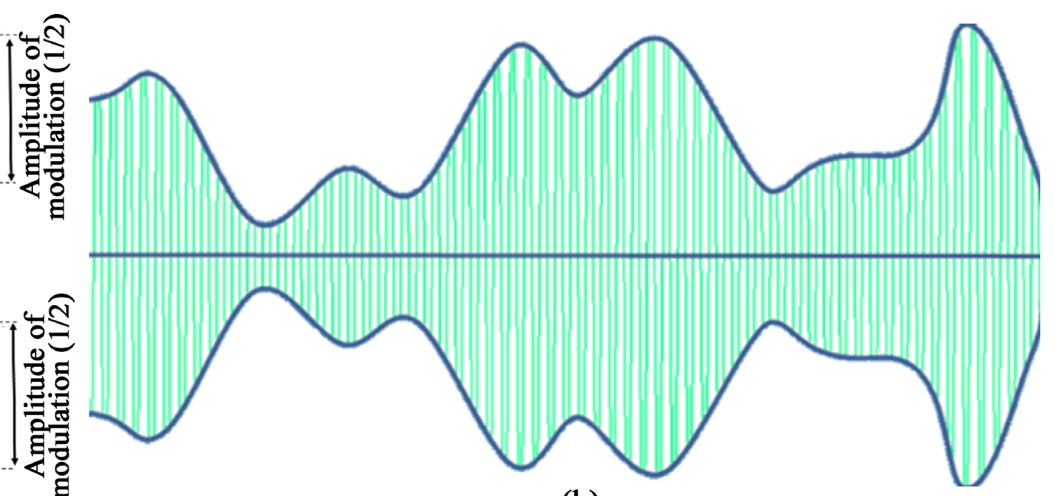

(b)

Figure 1. The amplitude modulated carrier frequency. (a) The modulation with a low-frequency periodic signal, (b) the modulation with a non-periodic signal with frequency variants. 
frequency is necessary. This noise could limit the accuracy of the measurements. However, in low frequencies, the large Warburg resistance also produces large electric noise because the electric noise of the resistance is proportional to the value of the actual resistivity [14].

The other advantage of the high frequency carrier is its impedance selection, which focuses the effects on the malignant cells, with the dispersion relation to attack the membrane rafts for exciting extrinsic signal pathways to apoptosis.

\subsection{The Modulation Process}

The electromagnetic interactions with real biological systems are faced with a heterogeneous, non-linear, and complexly regulated target. The in vitro (cell lines), the ex-vivo (tissue samples), the in-vivo (animal experiments), and human applications differ from each other due to the heterogeneity and organization of the biological target. The active regulation processes in the targets, which are complex, could change the electrolytes in the tissue, varying the inhomogeneities, causing further complications in the evaluation of the interactions. The heterogeneity of the targets influences the results; however the structure and function of the cellular membranes have strong similarities, which allows for the use of some unified considerations.

The average isolation of the various membranes in the tissues is enormous $\approx 10^{13} \Omega / \mathrm{m}$ [15]. It is so large that it can keep $\approx 70 \mathrm{mV}$ at a distance of $\approx 7 \mathrm{~nm}$, which is equivalent to ten million volts at a distance of one meter $\left(\approx 10^{7} \mathrm{~V} / \mathrm{m}\right)$, and its capacity is $\approx 10^{-2}(\mathrm{~A} \cdot \mathrm{s}) /\left(\mathrm{V} \cdot \mathrm{m}^{2}\right)=\mathrm{F} / \mathrm{m}^{2}$.

The cellular membrane, regulating the ionic transport of selected ionic species in and out of the cells. The idea corresponds to the triode or transistor when the current that flows through the device is non-linearly regulated with an intermediate action (net of base), which could amplify the time-dependent signal. The membrane is also a non-linear element [16]. Applying an RF signal on the membrane, it increases non-linearly Figure 2. The rectification is not ideal because a small amount of the opposite current also exists.

Measurement of the non-temperature dependent rectification (non-linearity) is not simple because it is not measurable through the living object when the integrity of the cells is intact. The current traveling through the cell meets twice with the transmitted signal, first from outside to inside the cell, and the second meeting is in the opposite direction. The two effects eliminate each other. The lipid bilayer, together with the ionic exchanges, completes the rectification phenomena [17] [18].

We had shown [19] the white noise excited linear system with infinite freedom, and cyclic symmetry emits pink noise. It works like a special filter creating $1 / f$ noise from the non-correlated white noise spectrum, which was measured [20].

The Fourier transformation of $x(t)$ pink noise is:

$$
F(f)=\frac{A}{i 2 \pi \sqrt{|f|}}
$$




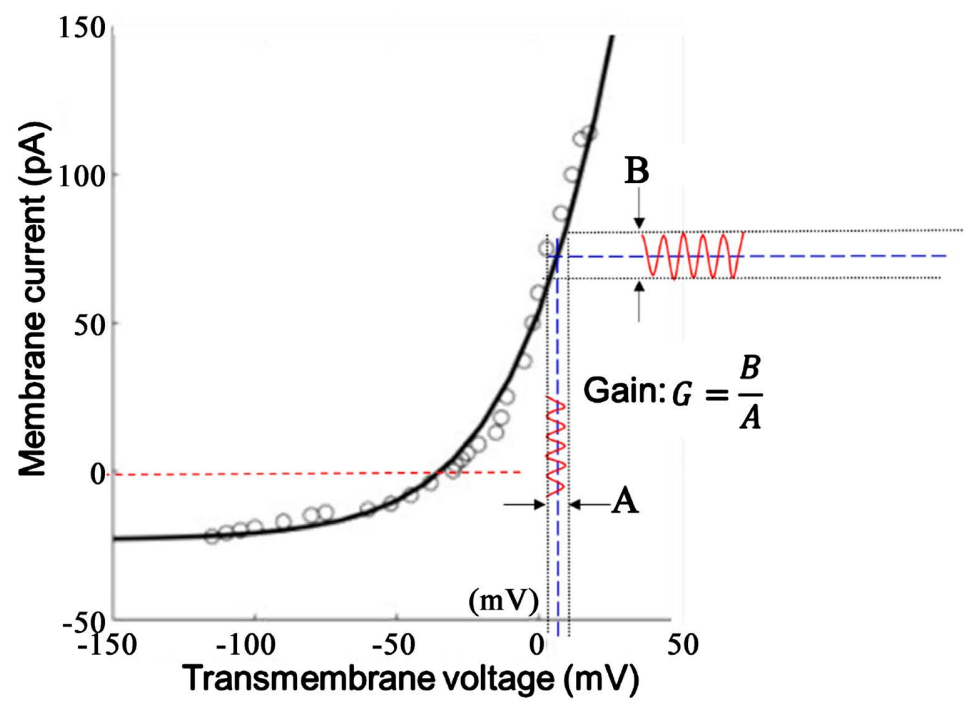

Figure 2 . The membranes of cells have enormously large polarization potential $(\approx 70 \mathrm{mV} / 5$ $\mathrm{nm}=1.4 \times 10^{7} \mathrm{~V} / \mathrm{m}$ ), which non-linearity rectifies the RF current. Due to the non-linearity, the rectification increases the signal amplitude $A$ to $B$ (gain: $G=B / A$ ).

where $A$ is the amplitude. The noise power spectrum:

$$
S(f)=F^{*}(f) F(f)=-i \frac{A}{2 \pi \sqrt{|f|}} i \frac{A}{2 \pi \sqrt{|f|}}=\left(\frac{A}{2 \pi}\right)^{2} \frac{1}{|f|}
$$

where the star is a sign of conjugation. Let be the signal function $v(t)$ of the carrier signal

$$
v(t)=U_{0} \cos 2 \pi f_{v} t
$$

where $f_{v}=13.56 \mathrm{MHz}$ is the frequency of the carrier, $U_{0}$ is its amplitude (voltage in electric signal). The $f_{v}$ carrier frequency is in the overlapping range of $\beta / \delta$-dispersions. The Fourier transform of the $y(t)=x(t) \cos 2 \pi f_{v} t$ modulated signal:

$$
Y(f)=\frac{1}{2} F\left(f-f_{v}\right)+\frac{1}{2} F\left(f+f_{v}\right)
$$

The Fourier transform of the pink noise modulated carrier is:

$$
Y(f)=\frac{1}{2} \frac{A U_{0}}{i 2 \pi} \frac{1}{\sqrt{\left|f-f_{v}\right|}}+\frac{1}{2} \frac{A U_{0}}{i 2 \pi} \frac{1}{\sqrt{\left|f+f_{v}\right|}}
$$

Physically, only positive frequencies can be realized, so the power spectrum is:

$$
S(f)=-i \frac{1}{2} \frac{A U_{0}}{2 \pi} \frac{1}{\sqrt{\left|f-f_{v}\right|}} i \frac{1}{2} \frac{A U_{0}}{2 \pi} \frac{1}{\sqrt{\left|f-f_{v}\right|}}=\left(\frac{A U_{0}}{4 \pi}\right)^{2} \frac{1}{\left|f-f_{v}\right|}
$$

The power spectra of pink noise and pink noise embedded in the carrier are shown in Figure 3. The noise power spectrum shifts to the $\omega_{0}=2 \pi f_{0}$ circular frequency of the periodic carrier.

\subsubsection{Amplitude Modulation-Stochastic Resonance}

Many chemical reactions have a coordinated subsequent chain, having a series of 
reactions in a definite order. This set is called the Markov process, a chain-like stochastic reaction-line. When the sequence of the realized states is such, each step depends solely on the state realized in the previous event Figure 4.

The biological processes have well-organized and controlled Markovian chain reactions, avoiding the sudden single-step liberation of energy during the catabolism. The series of effects in the time dynamics are Markovian. A two-state Markov process in which we assume that the coefficients can be influenced by an external electric field are described as follows:

$$
\begin{aligned}
& \frac{\mathrm{d} p_{1}}{\mathrm{~d} t}=-\alpha p_{1}+\beta p_{2} \\
& \frac{\mathrm{d} p_{2}}{\mathrm{~d} t}=\alpha p_{1}-\beta p_{2}, \\
& p_{1}+p_{2}=1
\end{aligned}
$$

where $p_{i}(i=1,2)$ is the probability of the actual state, and $\alpha$ and $\beta$ depend on the external electric field. This is the master equation of a Brownian particle bouncing back and forth in a potential well with two minima, excited by a force
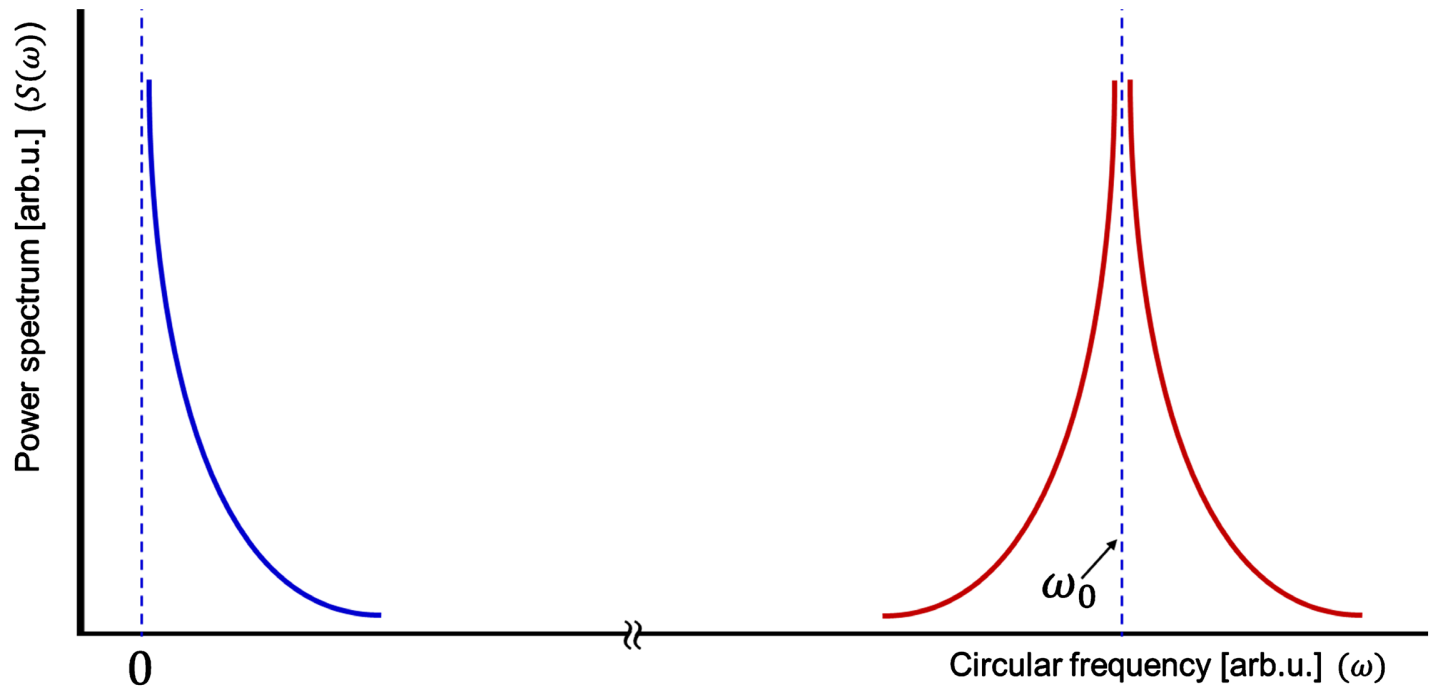

Figure 3. Power spectrum of pink-noise voltage amplitude modulated signal. The shifted pink-noise signal modifies the one-sided distribution towards symmetry around $\omega_{0}$.

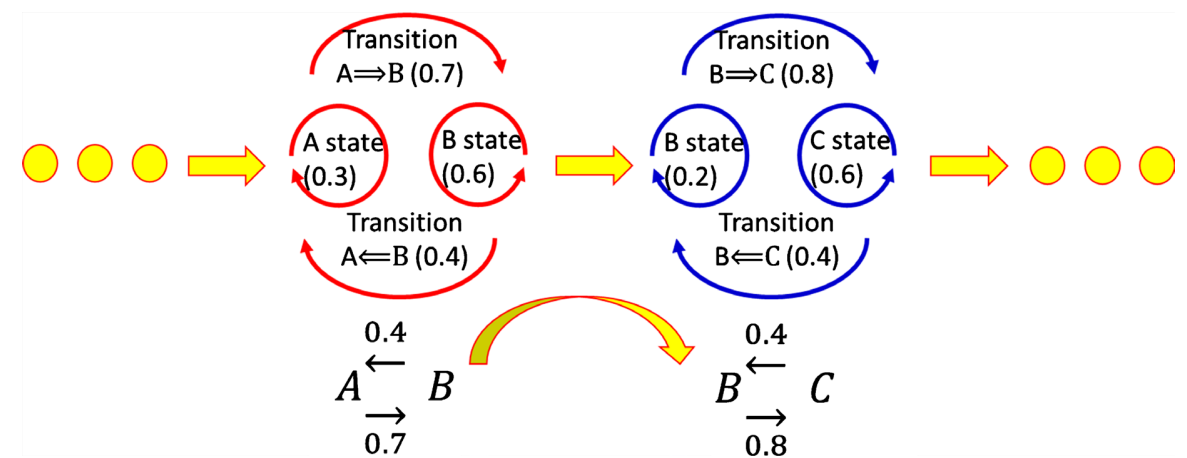

Figure 4. The Markov process is a sequential series of stochastic processes with individual reaction probabilities. 
of an external periodic field.

The cell works appropriately as long as the catalyst enzymes are not poisoned and, obviously, as long as the catalyst has something to catalyze. More specifically, although coenzymes provide a high degree of enzyme selectivity, there may be substances which have suppressor functions (enzyme poisons) that react in an opposite enzymatic way, or the coenzymes act to support the enzyme reaction (promoter function). On the other hand, when the cell actually does not have molecules to catalyze, the chemical reactions are terminated. We assume that the two states of the enzyme, $A$, and $B$, are stable but interchanging. The two states are the result of chemical reactions, with $\alpha$ forward, and $\beta$ backward reaction rate:

$$
A \underset{\beta}{\stackrel{\alpha}{\rightleftarrows}} B
$$

The concentration of the enzyme by $[A]$ and $[B]$ in confirmation states $A$ and $B$. Then,

the kinetic equations of the reaction in (9):

$$
\begin{aligned}
& \frac{\mathrm{d}[A]}{\mathrm{d} t}=-\alpha[A]+\beta[B] \\
& \frac{\mathrm{d}[B]}{\mathrm{d} t}=\alpha[A]-\beta[B]
\end{aligned}
$$

Enter the quantities in (10): $[T]=[A]+[B], \quad p_{1}=\frac{[A]}{[T]}, \quad p_{2}=\frac{[B]}{[T]}$, the equation has the same form as the master Equation (8).

The study of a voltage-gated ion channel defines $A \equiv O$, and $B \equiv C$, where $O$ is the open state and $C$ is the closed state. In this way, the kinetic equation of the ion channel is again the master Equation (8).

To determine the mathematical form of transient probabilities, we examine the stationary state of (8). Then, $\frac{\mathrm{d} p_{i}}{\mathrm{~d} t}=0$ so

$$
\frac{p_{1}}{p_{2}}=\frac{\beta}{\alpha}
$$

The energy of the two states $\pm \Delta E$ deviates from the reference level and assumes a Boltzmann distribution:

$$
\frac{p_{1}}{p_{2}}=\frac{\beta}{\alpha}=\frac{\mathrm{e}^{-\frac{E_{0}+\Delta E}{k T}}}{\mathrm{e}^{-\frac{E_{0}-\Delta E}{k T}}}
$$

We obtain the Arrhenius law for reaction rates from (12):

$$
\alpha=C \mathrm{e}^{-\frac{E_{0}-\Delta E}{k T}}, \beta=C \mathrm{e}^{-\frac{E_{0}+\Delta E}{k T}}
$$

With this, from (8), we get a differential equation; e.g., for $p_{1}$

$$
\begin{aligned}
& 2 \tau \frac{\mathrm{d} p_{1}}{\mathrm{~d} t}=-\left(\mathrm{e}^{\frac{\Delta E}{k T}}+\mathrm{e}^{-\frac{\Delta E}{k T}}\right) p_{1}+\mathrm{e}^{-\frac{\Delta E}{k T}}, \\
& 2 \tau=\left(C \mathrm{e}^{-\frac{E_{0}}{k T}}\right)^{-1}
\end{aligned}
$$


Apply Taylor series and stop at the first term, then

$$
\begin{aligned}
& \frac{\mathrm{d} p_{1}}{\mathrm{~d} t}=-\frac{1}{\tau} p_{1}+\frac{1}{2 \tau}-\frac{1}{2 \tau} \frac{\Delta E}{k T}, \\
& 2 \tau=\left(C \mathrm{e}^{-\frac{E_{0}}{k T}}\right)^{-1}
\end{aligned}
$$

When the field strength is a harmonic function of time, the energy depends on it linearly:

$$
\Delta E=a \sin \omega t
$$

From (15) and (16), we get

$$
\frac{\mathrm{d} p_{1}}{\mathrm{~d} t}=-\frac{1}{\tau} p_{1}+\frac{1}{2 \tau}-\frac{1}{2 \tau} \frac{a}{k T} \sin \omega t
$$

To find the form of the excitation, the stationary solution of the following inhomogeneous differential equation has to be determined:

$$
\frac{\mathrm{d} p}{\mathrm{~d} t}+\frac{1}{\tau} p=-\frac{1}{2 \tau} \frac{a}{k T} \sin \omega t
$$

which is

$$
\hat{p}(k T)=\frac{a}{2 k T} \frac{1}{\sqrt{\tau^{2} \omega^{2}+1}}=\frac{a}{2 k T} \frac{1}{\sqrt{1+\left(\frac{\mathrm{e}^{\frac{E_{0}}{k T}}}{2 C} \omega\right)^{2}}}
$$

The solution shows that the probability associated with such an excitation varies according to a harmonic function with time, regarding the noise intensity of the thermal background $k T$. It follows a sharp maximum at a given $f$ frequency as a function of $k T$ noise intensity Figure 5 .

Formulate this result oppositely: this also means that there is a frequency where the amplitude is maximum for a given noise level. The stochastic resonance rules also such microscopic molecular structural changes like the protein folding phenomenon [21].

\subsubsection{Demodulation Stochastic Resonance}

The modulated carrier signal targets the selected malignant cells, and the cells rectify (demodulate) the received signal. The demodulation is basically a rectification process, which uses stochastic resonance [22]. The decomposition of (14):

$$
\begin{aligned}
& 2 \tau \frac{\mathrm{d} p_{1}}{\mathrm{~d} t}=-\left(2+\left(\frac{\Delta E}{k T}\right)^{2}\right) p_{1}+1-\frac{\Delta E}{k T}+\frac{1}{2}\left(\frac{\Delta E}{k T}\right)^{2}, \\
& 2 \tau=\left(C \mathrm{e}^{-\frac{E_{0}}{k T}}\right)^{-1}
\end{aligned}
$$

Assume the field strength of the modulated signal is a harmonic function of time and let the energy depend linearly on it

$$
\Delta E=a(1+m \cos \Omega t) \sin \omega t
$$




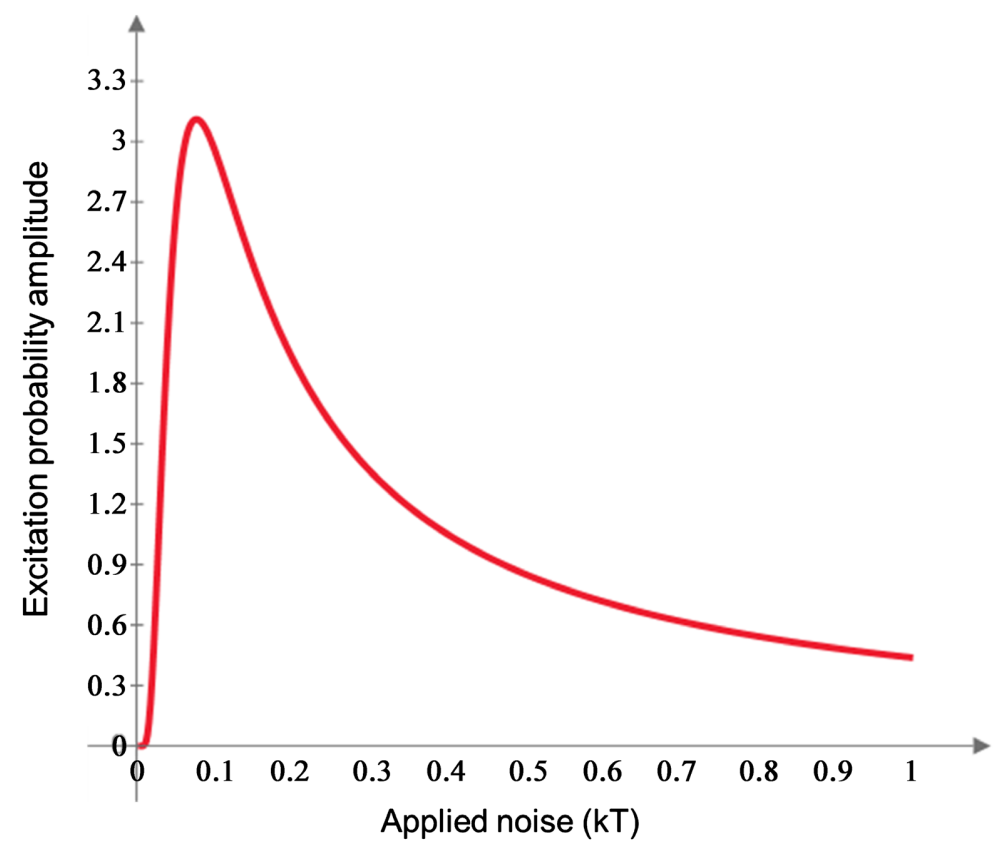

Figure 5. The change in the amplitude of the stochastic resonance probability as a function of the $k T$ noise intensity (Calculated by PTC MathCad).

where $m<1$, the modulation depth $\Omega$ is the modulator and the $\omega$ carrier frequency.

Substituting this into our previous equation, we get that

$$
\begin{aligned}
2 \tau \frac{\mathrm{d} p_{1}}{\mathrm{~d} t}= & -\left(2+\left(\frac{a}{k T}\right)^{2}(1+m \cos \Omega t)^{2} \sin ^{2} \omega t\right) p_{1} \\
& +1-\frac{a}{k T}(1+m \cos \Omega t) \sin \omega t+\frac{1}{2}\left(\frac{a}{k T}\right)^{2}(1+m \cos \Omega t)^{2} \sin ^{2} \omega t, \\
2 \tau= & \left(C \mathrm{e}^{-\frac{E_{0}}{k T}}\right)^{-1}
\end{aligned}
$$

As a function of probability over time, there is a slow change and a rapid fluctuation. The first is from the modulation, and the second is from the carrier.

We are only interested in slow change now. To filter this out of the above equation, we average it over the time of the carrier period. In this case, the slow signal can be considered constant for the time functions, and the time average can be replaced by the fast one.

Under this rule, the slow change is

$$
\begin{aligned}
2 \tau \frac{\mathrm{d} p_{1}}{\mathrm{~d} t}= & -\left(2+\left(\frac{a}{\sqrt{2} k T}\right)^{2}(1+m \cos \Omega t)^{2}\right) p_{1} \\
& +1+\frac{1}{2}\left(\frac{a}{\sqrt{2} k T}\right)^{2}(1+m \cos \Omega t)^{2}, \\
2 \tau= & \left(C \mathrm{e}^{-\frac{E_{0}}{k T}}\right)^{-1}
\end{aligned}
$$


equation describes.

Suppose the modulation depth is small. Then our above equation can be further simplified:

$$
\begin{aligned}
2 \tau \frac{\mathrm{d} p_{1}}{\mathrm{~d} t}= & -\left(2+\left(\frac{a}{\sqrt{2} k T}\right)^{2}(1+2 m \cos \Omega t)\right) p_{1}+1 \\
& +\frac{1}{2}\left(\frac{a}{\sqrt{2} k T}\right)^{2}(1+2 m \cos \Omega t)
\end{aligned}
$$

This is now a linear differential equation with variable coefficients.

Although there is a general solution to this, we are not going anywhere with it, so we will apply the method of successive approximation to the solution.

Since we are looking for resonance, we only study the effect of the harmonic excitation function:

$$
2 \tau \frac{\mathrm{d} p}{\mathrm{~d} t}+\left[2+\left(\frac{a}{\sqrt{2} k T}\right)^{2}+\left(\frac{a}{k T}\right)^{2} m \cos \Omega t\right] p=\left(\frac{a}{\sqrt{2} k T}\right)^{2} m \cos \Omega t
$$

Introduce the

$$
\begin{aligned}
& F(p):=2 \tau \frac{\mathrm{d} p}{\mathrm{~d} t}+\left[2+\left(\frac{a}{\sqrt{2} k T}\right)^{2}\right] p, \\
& f(p):=p\left(\frac{a}{k T}\right)^{2} m \cos \Omega t
\end{aligned}
$$

expressions that are continuous functions of $p$.

Steps of successive approximation:

$$
\begin{aligned}
& F\left(p_{1}\right)=\left(\frac{a}{\sqrt{2} k T}\right)^{2} m \cos \Omega t, \\
& F\left(p_{2}\right)=f\left(p_{1}\right), \\
& F\left(p_{i}\right)=f\left(p_{i-1}\right)
\end{aligned}
$$

Now it's true that

$$
\begin{aligned}
& F\left(p_{1}\right)+F\left(p_{2}\right)+\cdots+F\left(p_{i}\right)=F\left(p_{1}+p_{2}+\cdots+p_{i}\right) \\
& =\left(\frac{a}{\sqrt{2} k T}\right)^{2} m \cos \Omega t+f\left(p_{1}\right)+f\left(p_{2}\right)+\cdots+f\left(p_{i-1}\right) \\
& =\left(\frac{a}{\sqrt{2} k T}\right)^{2} m \cos \Omega t+f\left(p_{1}+p_{2}+\cdots+p_{i-1}\right)
\end{aligned}
$$

If the procedure is convergent, then if $i \rightarrow \infty$, the line proceeds to the solution, and due to the required continuity the above expression reduces to the simple equation:

$$
F(p)=\left(\frac{a}{\sqrt{2} k T}\right)^{2} m \cos \Omega t+f(p)
$$

Now let's look at the first approximation! This gives a solution of a smooth diff equation. 


$$
2 \tau \frac{\mathrm{d} p_{1}}{\mathrm{~d} t}+\left[2+\left(\frac{a}{\sqrt{2} k T}\right)^{2}\right] p_{1}=\left(\frac{a \sqrt{m}}{\sqrt{2} k T}\right)^{2} \cos \Omega t
$$

The amplitude of the variable probability according to the harmonic function with modulating frequency can now be determined as follows:

$$
\begin{aligned}
\hat{p}_{1}(R T) & =\left(\frac{a \sqrt{m}}{\sqrt{2} k T}\right)^{2} \frac{1}{\sqrt{4 \tau^{2} \Omega^{2}+\left[2+\left(\frac{a}{\sqrt{2} k T}\right)^{2}\right]^{2}}} \\
& =\left(\frac{a \sqrt{m}}{\sqrt{2} k T}\right)^{2} \frac{1}{\sqrt{\left[2+\left(\frac{a}{\sqrt{2} k T}\right)^{2}\right]^{2}+\left(\frac{\mathrm{e}^{\frac{E_{0}}{k T}}}{C} \Omega\right)^{2}}}
\end{aligned}
$$

It is a resonance again Figure 6.

\subsection{Effects of Modulation in Human Therapy}

The expected actions mark out the following basic goals:

1) Supports the healthy network over the unhealthy network.

2) Selectively targets the cancer.

3) Supports the immune system, boosts the homeostatic harmony and chains of reactions.

4) Excites the selected molecules in selected cells for special molecular and immunogenic changes.

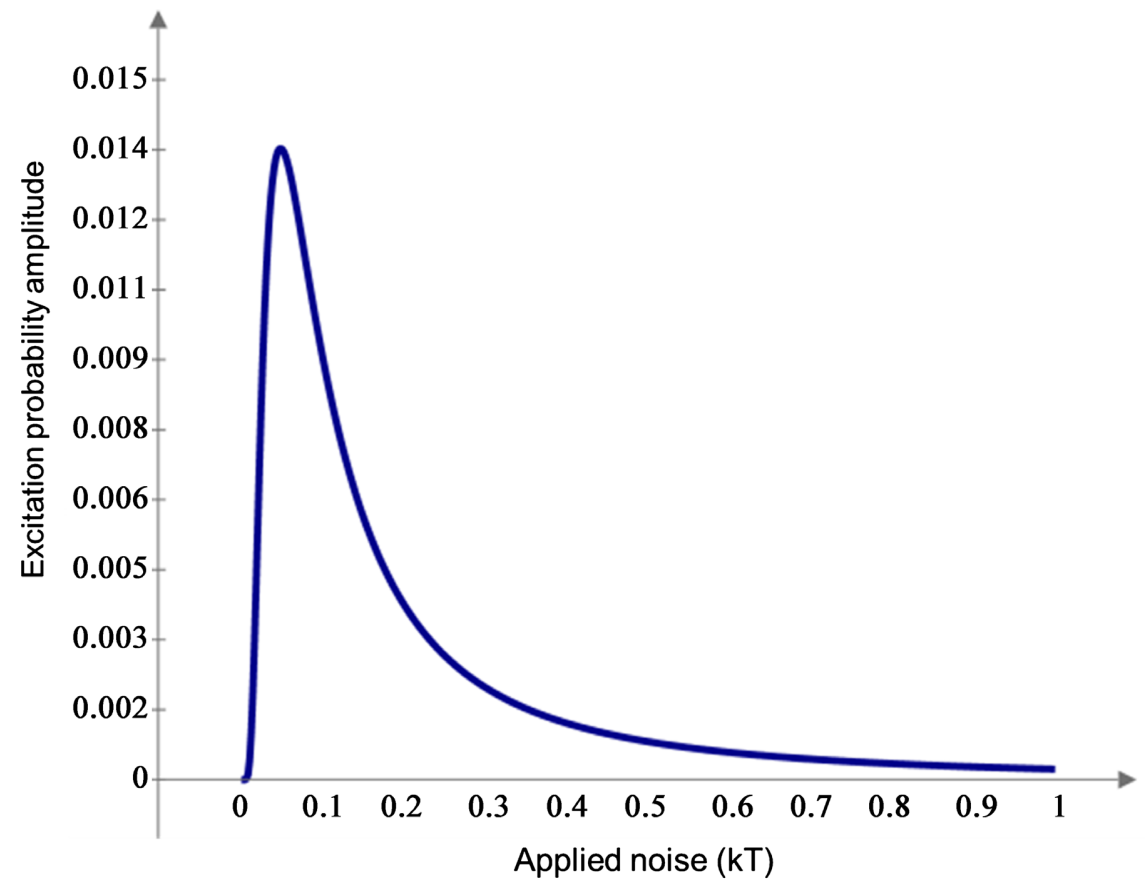

Figure 6. The amplitude of the demodulation stochastic probability depends on the noise intensity too (Calculated by PTC Math Cad). 
Due to the complex interconnection of the living objects, these effects are overlapping and are supporting each other.

In the following sections, we focus on emphasizing the features of modulation for fighting against cancer, which is a disease of the dynamic equilibrium breaking the multicellular cooperative network into unicellular individualism of the autonomic "selfish" cells. The task is twofold:

1) find and destroy the malignant cells. The intention is to act with the local treatment systemically, extend the task to the entire body;

2) force cellular homeostasis harmony with a homeostatic synchronization signal.

\subsubsection{Boost the Healthy Network}

The role of each cell supports each other in the cellular network in a tissue, there must be an interaction between them to realize this. One such possibility is the cyclic interaction in which the thermal noise is eliminated and instead a noiseless mode of information exchange appears [23]. When an abnormality occurs in cellular functions the cyclic symmetry locally brakes. The networked communication between the cells develops disturbances and that became noisy resulting in a break in the communication between cells. The thermal noise at least locally overtakes the healthy harmony. This is a change in the physiological information and is accompanied by broken psychological harmony causing a malaise state.

The social inclination is encoded by evolution into DNA. It is capable of creating a form of movement in which only noiseless modes are realized. As a result, two effects are realized, the noiseless communication, and harmony of physiochemical processes with stress and hormone dependent psychochemical ones. This later is a brain-controlled systemic process, fixing the well-being.

1) One of the crucial steps to re-establish the cyclic symmetry is the synchrony between the cellular activities. The self-synchronization of the chemical processes was observed in the famous Belousov-Zhabotinsky (BZ) reaction [24]. The BZ reactions are far from thermal equilibrium and evolve chaotic features [25], providing a chemical model of self-organized, synchronized but non-equilibrium biological processes and noise-assisted ordering [26]. The self-synchronization of chemical oscillators is also a known phenomenon [27]. An interesting example of neurological harmony is the synchrony promoted by the music affecting neuronal interactions merging the $\gamma, \beta$, and $\theta$ EEG signals as electrical synchrony [28]. Recognition of the harmony in $1 / f$ noise fluctuations in music [29], connected to the short-range autocorrelation of rhythms [30]. The synchrony between the living components and the connected, synchronized coupling in living organisms is essential, and the resonance is a highly effective way to achieve it [31]. When the living system functions normally, there are noiseless modes of internal communications. The environment is however noisy, and the living information exchange faces this challenge. This means that the system must work among various external noises and must be perfectly controlled, even in changing thermal white-noise resulting from temperature in a physiologic interval. 
This ensures the dynamic equilibrium, the homeostasis.

2) The physiological state includes a dynamic chemically driven psychological state in the living organism corresponding to well-being. The relationship between physiological and conscious processes has puzzled many researchers, including Schrödinger [32]. Apparently, the physicochemical processes that take place in each cell are the same, but the healthy cells are under the control of others in the network ("social" signaling [33]) which is a collective action. Social information should spread within the body without loss of information. This accompanied psychological process corrects the well-being. The realization of stochastic resonance indicates that the states of well-being are discrete. Their change is like a "resonance". Based on a finite number of distinguishable states of well-being, it is also likely that the number of modes of communication or modes of disintegration is finite.

The stored information passed down to the new cells through the individual DNA molecules regulates the organ's function, but cannot be designated as controllers of the described self-organized communication. Despite their ability to store all the information about the body in the nucleic DNA, the cells, due to the organ collectivity, use only those pieces of information appropriate to their tasks in the organ. The intranuclear DNA is a blueprint for the production of the new cell. This condition provides amazingly high safety in the functioning of the organ. The "social" communication allows the organ to function even when a part of it is damaged. This is essentially Neumann's concept of realizing a high-reliability system from low-reliability ones [34].

As the network becomes extensive, the communication signal goes over greater distances in an intensively noisy environment, so more and more information is being lost by distance. In the end, the cell cannot recover the received information. Beyond a limit, noise wins, no matter how good the noise-suppressing ability of the communication network of cells is. It can be assumed that the disintegration of the information network is a process similar to the phenomenon of stochastic resonance, i.e., the addition of a small amount of noise leads to the emergence of novel, primarily chaotic behavior. It is reasonable to assume that with stochastic resonance, that cell that lost its communication commits suicide, i.e., ends up with apoptosis.

The collective excitations comprise the non-local waves and activate the energy flow in the homeostatic networks. These excitations are mainly in the low-frequency range, and the expected frequency spectrum follows the natural $1 /$ f fluctuations [35].

The self-similar self-organizing process is collective [36] and relates to the scale-independent phenomena [37]. Terminals of a circulatory system to supply an organ adjacent to the cells are equivalent and supply the cells with the same functions equally. The collectivity subordinates the individual needs to the groups and optimizes the energy distribution for the best survival with the lowest energy consumption. This energy-share works like some kind of democracy [38]. 
One of the fundamental ordering principles for healthy living subjects is a characteristic "democratic" energy supply in their organisms for optimal energy consumption. The "democratic" idea is more general than just the energy supply. It characterizes the information distribution, as well [39].

This "democracy" is regulated by general biophysical rules, governed by the competition for resources in micro- and macro-phenomena, having intensive interaction with their environment. The goal of the multicellular living object is forming cooperation, optimizing the energy intake. Due to its energetically openness, the individual living object needs internal cooperative distribution of the incoming energy. The survival of its parts determines the overall survival of the object, so the optimization of energy distribution is crucial.

In healthy multicellular systems, numerous mitochondria help the individual cellular functions. Even the otherwise similar cells may vary substantially in their mitochondrial content, together with their size and membrane potential [40]. The variation arises from uneven partitioning at cell division, producing extrinsic differences in energy demand and supplied cellular processes [41]. The cells which have considerable energy demand for their normal function have a higher number of mitochondria. For example, the mitochondria fill up 20\% of the entire cell volume of human liver cells, and they work cooperatively to serve the extreme hepatocellular ATP demand [42]. The uneven mitochondrial density in different kinds of cells shows the energy distribution problem between the cells. The cells use different energies depending on their function, so the "democratic" distribution of energy between all cells equally obviously does not work. However, another kind of "democracy" works: the cells have well-controlled and balanced energy parts depending on their function in the collective. The structure of the entire system optimizes the energy distribution. The energy balance realizes a variation of the transport network supplying the variations of the demand. This directly requires that the fractal structure of transport is not unified as structure in the system, but of the formed or homeostatic demands.

The balancing of autocracy and democracy characterizes the evolution when the "selfish gene" [43] attempting to dominate all processes, but the environment-dependent self-organization requests democratic decisions; otherwise, the process blocks the system's complexity. The game with two actions to cooperate or defect well approaches the biological interactions [44]. The relevance of the strategies of such alternating games is sometimes more appropriate than synchronous games [45].

Moreover, the complex homeostatic control shows the balancing of feedback mechanisms. The negative-feedback interaction tunes to keep the actual state as close to the accurate value, determined by the self-organizing system. Nevertheless, the system is energetically open, which is the mandatory condition for life, so the positive feedback mechanisms force some reactions, determining the metabolic processes in both directions (catabolism and anabolism). This obligatory 
constraint derives a certainly autocratic line when the probability of reactions drives the defined direction so the processes. Such necessary autocratic strategies can be beneficial for exerting control over asymmetric interactions [46]. The regulatory networks have many similarities, from microbes to humans [47]. The regulation of collaboration and cooperation massively boosts the democratic character with overall genomic complexity. The regulatory effects in complexity have a propensity to a partnership supporting the democratic structure, whereas others regulate primarily in isolation, in a more autocratic fashion [48]. The degree of collaboration forming autocratic, in opposition to democratic, behavior is a specific character of the complexity in the open living systems.

Considering the complexity, the compulsory synchronization attempt by external modulated electric forces looks like a promising strategy in the cases when the collective harmony (the homeostatic regulation) is lost.

\subsubsection{Selecting Mechanisms}

The biochemically masked, hidden tumor cells show biophysical peculiarities. This biophysical evidence is not enough to turn the immune attention on the tumors but could select them and force the selected cells to show their factual genetic errors.

The first recognizable feature is their enlarged metabolic rate. Due to the intensive proliferation, the energy demand of these cells exceeds the rate of their healthy hosts. The ion transports in their environment increase the conductivity as a result of the higher ionic concentrations. So the adequately chosen RF current has a higher current density in the tumor region, where the electric conductivity is higher than in the healthy host. The high current density in tumor allows for the use of the RF energy to act selectively on cancer and host tissues.

The impedance measurements on Erlich solid tumors [49] identifies the particular fractal structure of malignancy. As the above discussions explained, the malignant specialties dynamically lower the conductivity of the tumor and the definite percolative self-similarity, with a lower impedance than the healthy host [50].

The biophysical selectivity has another distinguishing phenomenon due to the cellular autonomy of cancer cells [51] [52]. The intensive proliferation forms the autonomic feature of the cancer cell. The cytoskeleton of the cells frequently collapses and re-polymerises due to frequent fission. The intercellular connection is connected to the mitotic spindle [53], so the dividing cell breaks its connections with the neighbors during the division process [54]. Autonomy is a perfect concept as a hallmark of malignant cells. However, this hallmark formulates a more uncomplicated situation than the complex process works in reality [5].

Nevertheless, one factor of this phenomenon offers a selection possibility, the weakening or complete loss of the networking connections of these cells to their neighbors. The loss of the cadherin intercellular links promotes tumor growth [55], and allows increased motility of the cells [56], and changes the microenvi- 
ronment around it. The rearrangement of the structure in this region, due to the autonomic behavior, changes the dielectric permittivity, distinguishing these cells' changed impedance from the healthy cells [57]. The modified environment makes the cell recognizable by the RF-current, which flows through the selected tumor.

The third selective factor uses the modified structure of the tissue's pattern, which is a usual experience of the pathologists to identify the stage and prognosis of the malignancy. The pattern changes the impedance for the RF-current, and also its reaction to the modulation of the carrier frequency fundamentally differs when it forces healthy harmony. The well-chosen modulation delivers such a time pattern, which corresponds with the homeostatic dynamism, and is synchronized with some basic phenomena. But, the cancer is out from this harmony, and the modulation drastically differs from their dynamic properties. There is a simple analogy to represent this process with the pushing of the swing in the playground. When the push is in harmony with the swing's pendulum, it keeps moving with a small amount of energy; however, when the energizing push is out of harmony, considerable energy is lost, and the swing loses its kinetic energy. The applied modulation (synchronization) strategy has to be harmonized with the homeostatic regulation of individual systems.

\subsubsection{Control the Autonomy of Cells}

Distinguishing the networked, and individual cells was studied in detail by the Nobel Laureate A. Szent-Gyorgyi. He applied an etiological approach: how does the cellular collectivity disappear [53]? He focused on the pyruvate metabolic pathways for ATP production. He termed the cell which uses the pyruvate dominantly on fermentative way $\alpha$-state, which characterized the start of cellular evolution when no free oxygen was available [58]. This developmental period was unicellular, with the simple operation of life and replicated as much as possible. These individual cells compete for their demands; acting autonomously, without any cooperative communication. The appearance of free oxygen changed the game of life and made it possible to develop cooperative multicellular units, called $\beta$-state. The energy production was taken by a "power plant" in the cell, the mitochondria. Intensive diversity of life was available. The cooperatively connected cells in $\beta$-state share the tasks of living processes, to optimize the efficacy of the life.

The evolution on the cellular level is explained by an interplay of $\alpha$ - and $\beta$-stages [53]. The regular cooperative system in $\beta$-stages interrupted by the reproduction process when the cell breaks its collective functions, became an individual ( $\alpha$-state) to produce its daughter cells, and after this, integrates with the new cells into the system forming $\beta$-states. So the $\alpha$-state locally terminates the multicellular cooperative complexity. The cooperative living complexity easily and naturally transforms into a basic, dividing $\alpha$-state. When the network is broken, the system becomes unstable, parallel with stable, independent cells in $\alpha$-state form [59]. The cells in $\beta$-state are cooperative, energizing themselves with 
oxidative metabolism provided by their mitochondria. Their division should be strictly controlled by the networking cells and dynamic processes.

Normal cellular division transforms locally the $\beta$-state to $\alpha$-state, which is a normal process in the multicellular system, although it hurts the systemic collectivity in that local volume. Irregularity happens when the dividing cell remains in $\alpha$-state, because the individual local conditions prefer autonomy, which ensures a high amount of energy intake to the cell. The long-time optimal collective demand overcame the individual interest of the cell. This state develops cancer which is regarded as "dismantling of multicellularity" [60].

The embryonic cellular organization could be a model of how the cancerous cluster can be stabilized. The "renegade" single-cell [61] is the cell born with a genetic deviation allowing its further development to remain individual. This behavior could be the starting step of forming a malignancy. The driving principle is the mass-dependent allometry of tumor mass [62]. The observed scaling follows from the linear dependence of the relative changes of the parameters. In general, when $c$ is a constant and $a$ and $b$ are the parameters, then:

$$
\frac{\mathrm{d} b}{b}=c \frac{\mathrm{d} a}{a}
$$

The (32) scaling is observed in the allometric comparison of the various living masses and their metabolic rates [63], where the basal metabolic rate of tumor $\left(B_{c}\right)$ is proportional with $3 / 4^{\text {th }}$ of the $M$ mass of the tumor: $B_{c} \propto M^{3 / 4}$, so the metabolic rate for unit volume:

$$
\frac{B_{c}}{M} \propto M^{-1 / 4}
$$

On the other the lifespan $T$ of the tumor also has approximately the same dependence from the mass [64]:

$$
T \propto M^{1 / 4}
$$

Note that the universality of the values of exponents has intensive debates [65] [66] [67]. However, there is a consensus that the exponent $\alpha<1$. This also means that as the final mass increases, the metabolism of unit mass decreases, and at the same time, the mortality rate of the cells lowers. Compare the approximated lifespan of tumor $\left(T_{\text {tumor }}\right)$ and the healthy part of the body $\left(T_{\text {healthy }}\right)$, using the estimate in (34):

$$
\frac{T_{\text {tumor }}}{T_{\text {healthy }}}=\left(\frac{M_{\text {tumor }}}{M_{\text {healthy }}}\right)^{\alpha}
$$

where $\alpha<1$ (most frequently it is $\alpha \cong 1 / 4$ ) and $M_{\text {tumor }}$ and $M_{\text {healthy }}$ are the mass of tumor and the healthy body part which is affected by the tumor, respectively. It is obvious, that $M_{\text {tumor }}<M_{\text {healthy }}$, so from (35)

$$
\frac{T_{\text {tumor }}}{T_{\text {healthy }}}<1
$$

We assume that the regulators of complete homeostatic control (proliferation, 
morphogenesis, physiology, immune system, etc.) have an intervention time varying according to (34). As a result of (36), the regulation time of the tumor is shorter than the healthy reaction. Hence, the tumor reacts quicker than the healthy regulation system, so its growth escapes from the standard supervision. The consequence of this is that the regulators in the body are unable to control an activated cancerous cellular cluster.

Since the embryonic cell must be connected to the food network of the adult body, it must develop and increase in its direction by a known mechanism of vascularization. But in the adult body, it is also slow as it has adapted to the adult body. The process goes through the genetic instability of cancer [68] [69]. The p53 gene is the guardian of the genome. It ensures that the genome is stable for the long term. This requires that the p53 gene maintains the appropriate level of p53 protein in the intracellular space. A change in environmental conditions is a stress effect. When it persists for a long time, permanent stress is created. Inflammation and hypoxia are lasting stress effects, reducing the level of p53 protein in the cell. The weakened stability of the genome is observed by inflammation [70], and hypoxia [71], and so increased likelihood of mutations appears. The bystander effect produces precancerous cells in the neighborhood of the cells with intensive permanent stress and the consequent genetic instability [72]. The control needs re-regulation of the tumorous area locally and also systemically [73].

\subsubsection{Excite Selected Molecules}

The special autonomy and high metabolic activity of the malignant cells allow recognition, and the selection and attack of them. The energy provided with the carefully chosen RF current targets the selected cells and excites a few chemical changes in the selected malignant cells.

Electromagnetic selection of the malignant cells guides the energy delivery. The living targets are inherently heterogenic in thermal and electric properties, so the structural selection at the cellular level needs additional selection to target the chosen heterogeneity of the malignant cells. For this, we have to choose the carrier frequency, acting on different parts of the tissue structure. The applied RF current triggers various processes, which are often grouped in dispersion regions by frequency, defined by the main character of the bio-electromagnetic exchanges.

The $\beta$-dispersion ( $\sim 1 \mathrm{kHz}-\sim 100 \mathrm{MHz}$ broad spectrum) is linked to the cellular structure of biological materials [74]. It occurs at the interface of membrane-electrolyte structures, using Maxwell-Wagner relaxation [75]. The effect is an interfacial polarization of the cell membranes [76], resulting in the charge distribution at the cellular of interfacial boundaries [77]. The time dependence of the charge accumulation causes the characteristics of the $\beta$-dispersion [78]. In an experiment with sacrificed haddock muscle [79], the $\beta$-dispersion increases after a few hours of the sacrifice of the animal, showing the mechanism more connected to the cells than to the intact tissues. The high end of $\beta$-dispersion 
differs from the main effects of the range, called $\beta 1$-dispersion caused from the torque of biological macro-molecules representing significant dipole moments, like proteins, orienting these against the disordering force of the thermal background [80]. However, the large molecules have limited possibility to follow the applied frequency and to grow further. Due to the massive heterogeneity of the biological tissues, this dispersion could have multiple effects, depending on the excited molecules. The conformational change of the present polymers [81], and macro-molecular relaxation with the exchange of the ionic effect in the vicinity of them [82]. The relaxation of amino-acid chains [83] and the proton fluctuations [84] also could have a role, which has no significant importance [85].

The upper tail of the $\beta$-dispersion continues to the $\delta$-dispersion $(\sim 1 \mathrm{MHz}-\sim 1$ $\mathrm{GHz}$ ), which represents another mechanism. The $\delta$-dispersion occurs at a distinguished frequency range above the main $\beta$-dispersion [86] and is connected to the dipolar moments of proteins and other large molecules (like cellular organelles, biopolymers) [87]. This second Maxwell-Wagner dispersion $(\delta)$ is characteristic of suspended particles surrounded by a cell [88]. Proteins also cause these effects, protein-bound water and cell organelles such as mitochondria [89] [90].

Other relaxation processes like those of molecular side chains, bound water molecules, diffusion of charged molecules, and near membrane bonds, could be added to the $\delta$-dispersion.

In addition, the $\beta / \delta$-dispersion of the chosen carrier frequency orients the attack on the membrane reaction of the impedance selected cells [91] [92]. The optimally chosen carrier frequency is in the interval of intensive overlap of $\beta$ and $\delta$ dispersion and using in a practical point of view is an ISM-frequency 13.56 MHz. (The ISM spectrum is reserved internationally for industrial, scientific, and medical use.) The model calculation also shows the importance of the 13.56 $\mathrm{MHz}$ [93]. The chosen modulation enhances the selection. The RF energy dominantly absorbs on the clustered transmembrane proteins (rafts) [94], exciting their receptors [95]. The excitation destructs the malignant cells dominantly in an apoptotic way [96] Figure 7.

\subsubsection{Support the Immune System}

Homeostatic dynamic equilibrium is too complex for external constraints to be effective in repairing it. Tightly connected feedback mechanisms regulate the system, and the reaction of homeostatic control is against any simple constraints. An excellent example of this is the response to conventional hyperthermia, which aims to kill the tumor by the thermal effect of the absorbed energy. The heating is a valid objective, but unfortunately, homeostatic control mechanisms begin to correct this heating through various actions to maintain thermal balance. The most effective reaction is increased blood flow and perfusion, which aims to cool the heated lesion. However, this feedback carries a danger, as it increases the delivery of nutrients to the tumor and promotes metastasis by cell invasion into the bloodstream. 


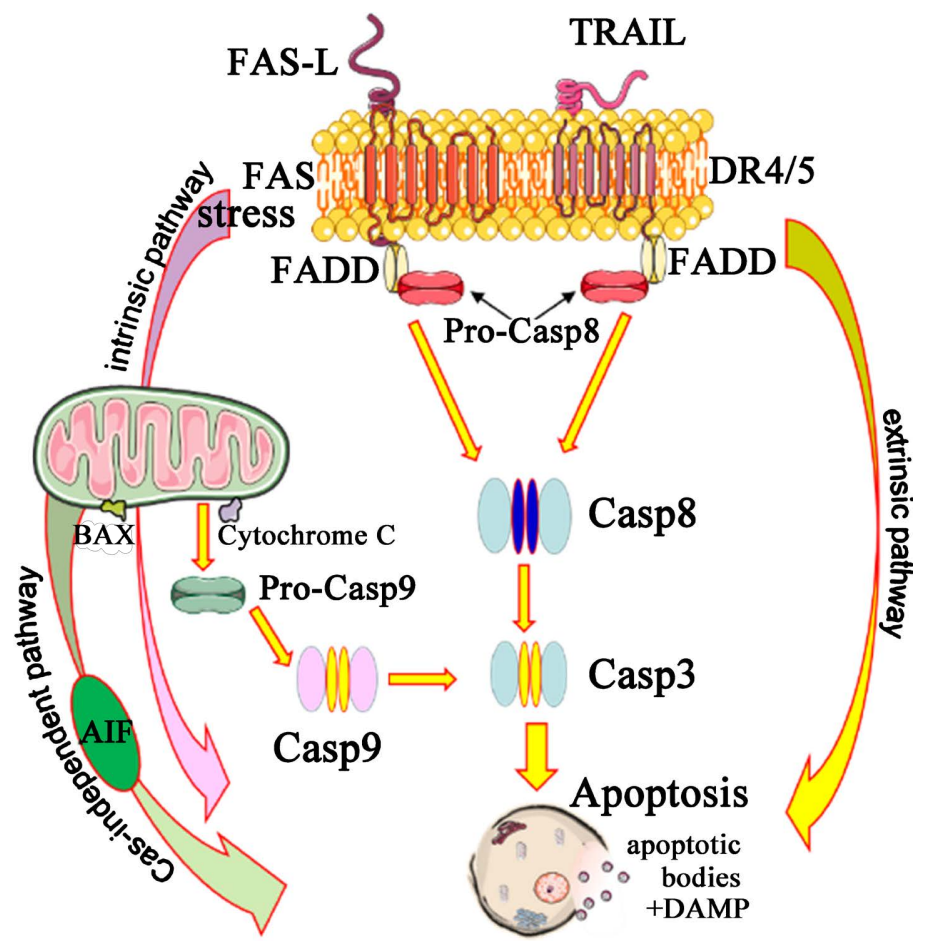

Figure 7. The extrinsic energy absorption excites the TRAIL death receptor and induces extrinsic, caspase-dependent signal transduction to apoptosis. The stress induces double intrinsic signals going on caspase-dependent and independent pathways.

Consequently, any winning strategy to influence the dynamic equilibrium must work in conjunction with homeostatic controls, utilizing natural processes and supporting the immune system to recognize and destroy malignant cells throughout the body. The preparation of the immune system could be a perfect target for oncology treatments, instead of targeting cancer's main strength, its proliferation. In this case, the lack of adaptive immunity to tumors can be revised, and the malignancy can be attacked by the host system itself.

The malignancy lacks the homeostatic complexity, turning the structural and dynamic conditions out of the healthy homeostatic network. Consequently, the challenging general tasks are fighting against cancer and the immune surveillance to support healthy homeostasis. The situation is complicated because the tumor cells hide their genetic information from the immune surveillance. They are well masked to avoid any systemic action against then, even the opposite: their demands are met as the system attempts to correct the irregularities. These "cheats" mislead the regulative actions and start to support the malignant cluster. Due to this falsely presented tumor status, the regular immune system does not act against it. The primary task is to present the signs of danger and stimulate the immune action to target and destroy the dangerous, highly proliferation cells.

The critical point is the immunological recognition of the malignancy. The immune system needs recognizable signs to direct its actions. However, the highly adaptive hiding strategy of malignant cells protects them from being identified by immune cells. A practical possibility for cancer invasion is the in- 
nate antitumor immune action of NK cells [97] [98]. Natural Killer (NK) cells do not need information through the host's histocompatibility complex 1 (MHC-I) molecules and act in the absence of priming. The cytotoxic activity of NK potentially controls tumor growth [99]. To complicate the complement of the available positive effect of NK cells, it could also promote tumor progression and angiogenesis [100] by inducing Reactive Oxygen Species (ROS) dysfunction [101]. The NK-cell activation could be achieved with a low-frequency electric field [102] as well as by electroporation [103]. Intensive low-frequency components in the spectrum of the modulated treatment may trigger the NK activity, enriching the NK cells in the targeted, selected tumor [104].

As a standard in immune homeostatic regulation, all processes have promoters and suppressors, so in complexity, every effect maybe a friend or foe, which appears for NK cell activity as well [105].

The modulation also may effectively support the healthy additive immune effects with developing tumor-specific immune reactions. The challenge is how to present the genetic information of the malignancy in order to ignite the immune system. One of the possible solutions would be immunogenic cell death (ICD). The main point is the particular apoptosis starting with an external signal with the electric field, exciting the Trail R2 (DR5) death receptor with FADD-FAS complex, and the external signal through caspase (Cas) pathway goes to Cas 8 and Cas3 finishing in apoptosis [106]. The external signal pathway connects to the internal mitochondrial apoptotic path as well, and forms Bax and cytochrome-c (point of no return) through Cas9, and Cas3 [107] finishing in apoptosis again [108]. The internally excited apoptosis also can follow the caspase-independent pathway through apoptosis-inducing factor (AIF) [104], so the apoptotic end can be reached by three different signal pathways. The XIAP protein could block the main external signal path, but the modulated RF blocks this XIAP activity with Septin4 [109], and with the same function, the SMAC/Diabolo [106].

All of the above processes develop damage-associated molecular patterns (DAMP) [106]; as a factor of the immunogenic cell death (ICD) [108]. The cancer cells, during its apoptosis, in addition to apoptotic bodies, liberates calreticulin (CRT, “eat me” signal), HMGB1 (“danger” signal), and heat-shock protein 70 (HSP70, “info" signal). These processes prepare antigen recognition producing antigen-presenting cells (APCs), which trigger the presence of helper (CD4+) and killer (CD8+) T-cells with explicit recognition of the malignant cells over the body [110]. This process allows the attack of distant micro- and macro-metastases in the system (abscopal effect), turning the local treatment to systemic [111] [73]. Noteworthy, the addition of dendritic cell medication may boost the overall immune effects [112] [113], and also an independent immune-stimulator works in harmony with modulated treatment [110]. Figure 8 shows the schematic summary of the immune processes.

\subsubsection{Use Non-Thermal Effects}

The amplitude modulation $(\mathrm{AM},<20 \mathrm{kHz})$ of the $\mathrm{RF}$ carrier frequency can 


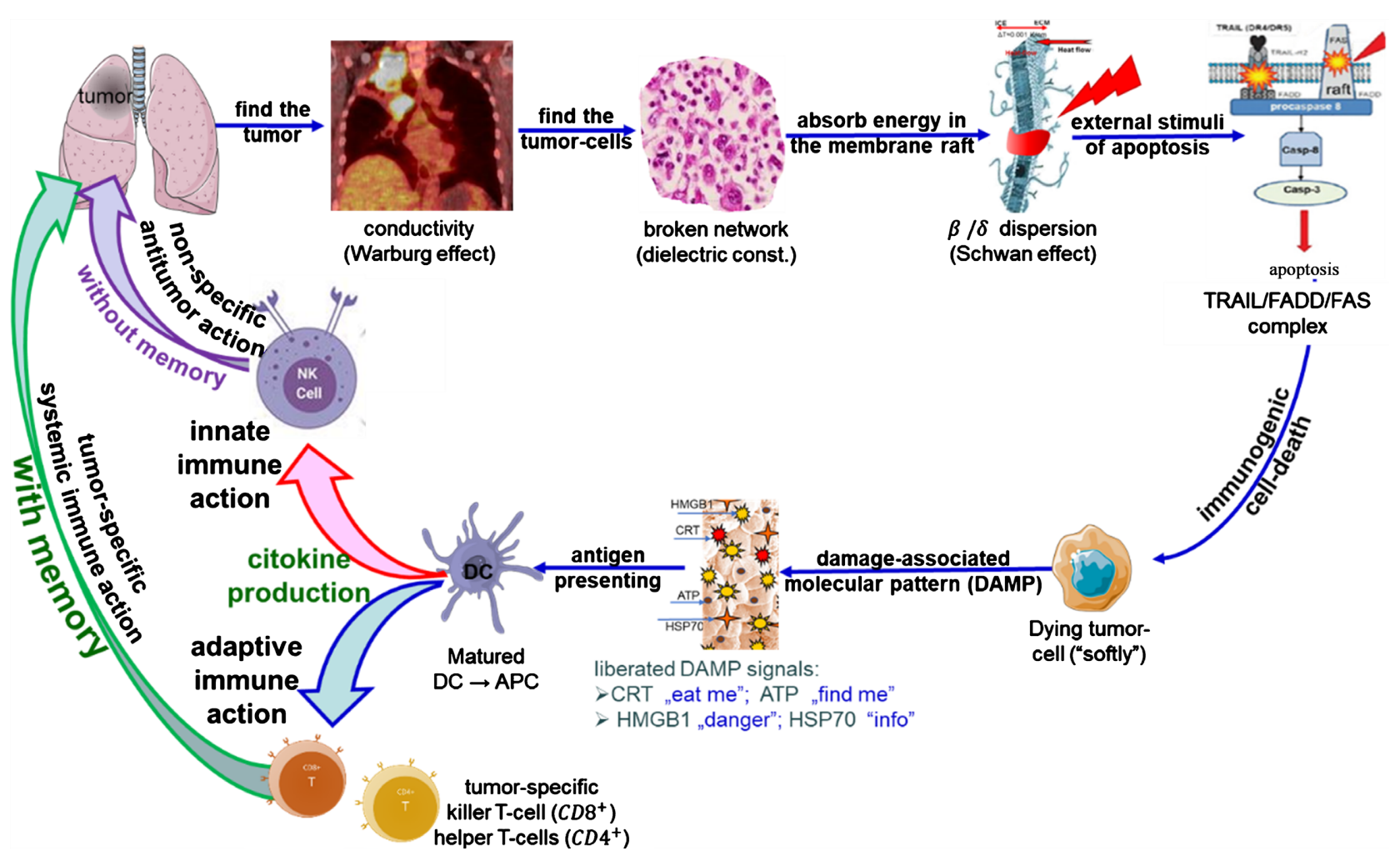

Figure 8. The modulated electromagnetic carrier selects the tumor cells and excites the membrane rafts inducing apoptosis. The special process is immunogenic, and the dying tumor-cell produces damage-associated molecular pattern with calreticulin (CRT), ATP, HMGB1 and HSP70; which generate antigen presentations in lymph-nodes and develops adaptive and innate immune reactions to attack the tumor.

intensify the tumor-specific absorption as a part of the selection mechanism [114]. Despite that, by a theoretical approach of the little energy absorption [115], the membrane demodulation effect could cause damages in the cytosol [116], or trigger apoptotic signals and destroy the cell [106]. The result of the non-thermal processes is the change of the chemical or structural situation in the targeted (investigated) compound assembly [117]. The non-thermal processes form a new phase (structural or chemical), which is a phase transition. The transition does not use heat from the field but directly uses the work of the electric field for the actual changes by absorption. The energy from the applied electric field is absorbed by the electrons or any other particles in a compound. It could be done without temperature change, but the phase of the material alters and the entropy changes without adjusting the temperature.

This phenomenon, however, has two connections to the temperature:

1) We know that $100 \%$ energy efficacy does not exist (entropy law), so the "lost" energy (which is kept as internal energy of the system) produces heat as well.

2) We know that the changing temperature changes the conditions of the "non-thermal" processes, which are in this way sharply dependent on the temperature. In other words, the reaction rate changes in the simplest case by the Arrhenius law. This complex process, which contains the thermal dependence of 
the "non-thermal" effect (transition effect), is described by Eyring transition state theory, which is proposed to describe the hyperthermia where this complexity appears. In Eyring's description, the thermal part is the same as in the Arrhenius law. Still, it has a part, which is a structural dependent factor, which could change without any temperature change, describing the "non-thermal effect" in complex systems.

The DNA damage is non-thermal. It is a phase transition, which has to be fixed by oxygen or by blocking the repairing enzymes. It does not need a temperature change at all. However, we know that both the oxygen-related or enzymatic fixing reactions (which conserves the break as it is) are temperature-dependent. The oxygen and enzyme reactions rapidly change according to temperature, mostly with Arrhenius law. The radiotherapy result has two parts: a temperature-independent and a temperature-dependent part, in the same way as this model describes the modulated electro-hyperthermia (mEHT) effect. This is why the same dose (Gray) is proposed for both the radiation processes (radiotherapy: ionizing; and mEHT: non-ionizing radiation).

\section{Results-Applications}

The dynamic structures, performing random stationary stochastic self-organizing processes, have practical applications in recognizing the diseases [118] [119]. The self-similarity used modeling of cancer by fractals [120], described by a generalized model [121]; helping to evaluate the various images in oncology [122]. The collectivity of the organization of the biological systems could be monitored by the fractal concept [123]. The fractal geometry describes the pathological architecture of tumors and their growth mechanisms accompanying time-dependent processes [124], and prognostic value [125].

The pink-noise modulation applies the fractal knowledge to support the harmonization efforts of homeostatic regulation and induce stochastic resonance near the frequency of the carrier, to demodulate and excite the desired signal pathways. The intensive backing of the heathy influence on the cancer is mandatory because the tumors are out from the structural and dynamic coordination of the natural organizing control.

Technically a high frequency (RF) carrier delivers the well-chosen time pattern of the modulation, which transports the modulated signal to the body with a carefully fitted applicator [126]. The applicator is driven by a voltage signal formed, as shown in Figure 9.

The spectrum and the power density of the signal which drives the applicator are studied by decomposing the applicator voltage into a signal $s(t)$ and a noise component $n(t)$ :

$$
\begin{aligned}
& u(t)=s(t)+n(t), \\
& s(t):=U_{0} \sin \omega_{0} t, \\
& n(t):=m z(t) U_{0} \sin \Omega t
\end{aligned}
$$

To calculate the power spectrum, we need to construct the autocorrelation 


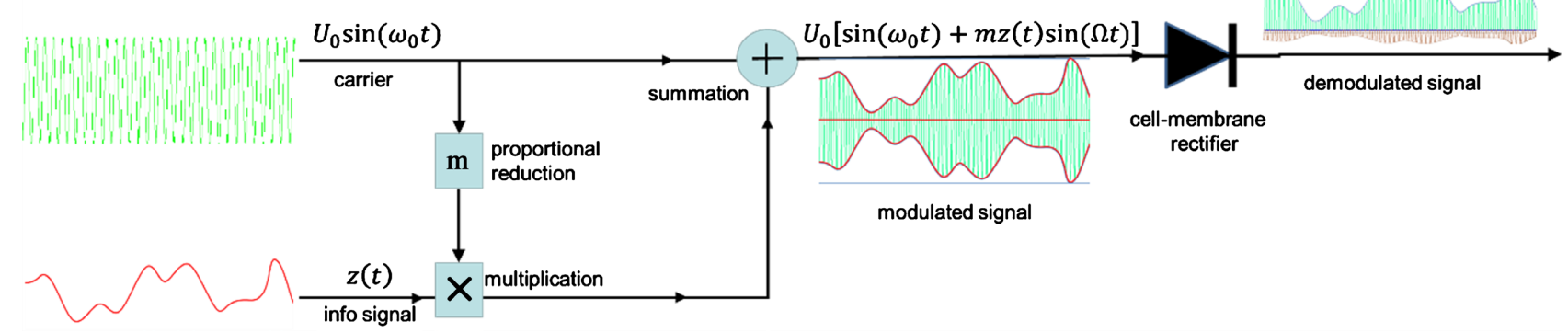

Figure 9. Principle of amplitude modulation with pink noise the $\Omega$ is the carrier circular frequency, $U_{0}$ the carrier amplitude, $m$ is the modulation depth, and $z(t)$ is the pink noise.

function $u(t)$ :

$$
u(t) \otimes u(t+\tau):=\lim _{T \rightarrow \infty} \frac{1}{T} \int_{-T}^{T} u(t) u(t+\tau) \mathrm{d} t
$$

where the sign $\otimes$ notes the necessary time integration of the signal with self in $\tau$ time-lag, and where we have taken into account a sufficiently sizeable averaging time. Considering the signal and noise components, we get:

$$
u(t) \otimes u(t+\tau):=s(t) \otimes s(t+\tau)+n(t) \otimes n(t+\tau)
$$

where the average of the function formed by the product of signal and noise approaches zero. First, the properties of the $F\{f(t)\}$ Fourier transformation of the correlation function has to be calculated:

$$
\begin{aligned}
& F\{f(t) \otimes g(t+\tau)\}=F(\omega) G^{*}(\omega), \\
& F\{f(t)\}=F(\omega), \\
& F\{g(t)\}=G(\omega)
\end{aligned}
$$

where the * star notation is a sign of conjugation. The Fourier transform is the pink noise in this approximation, so:

$$
F\{z(t)\}=Z(\Omega)=\frac{1}{i \sqrt{\Omega}}
$$

thus the Fourier transform of noise:

$$
F\{n(t)\}:=\frac{i}{2} m U_{0}\left[Z\left(\left|\omega_{0}-\Omega\right|\right)\right]=\frac{i}{2} m U_{0}\left[\frac{1}{i \sqrt{\left|\omega_{0}-\Omega\right|}}\right]
$$

consequently, the voltage power spectrum of the applicator:

$$
\begin{aligned}
\Phi_{\text {ии }}\left(\omega_{0}\right) & :=F\{u(t) \otimes u(t+\tau)\}: \\
& =U_{0}^{2} \delta\left(\omega_{0}-\Omega\right)+\frac{m^{2} U_{0}^{2}}{4} \frac{1}{\left|\omega_{0}-\Omega\right|}
\end{aligned}
$$

Figure 10 shows the modulated signal spectrum.

According to the Wiener-Khinchin theorem [127], the square of the voltage amplitude in the frequency interval is: 


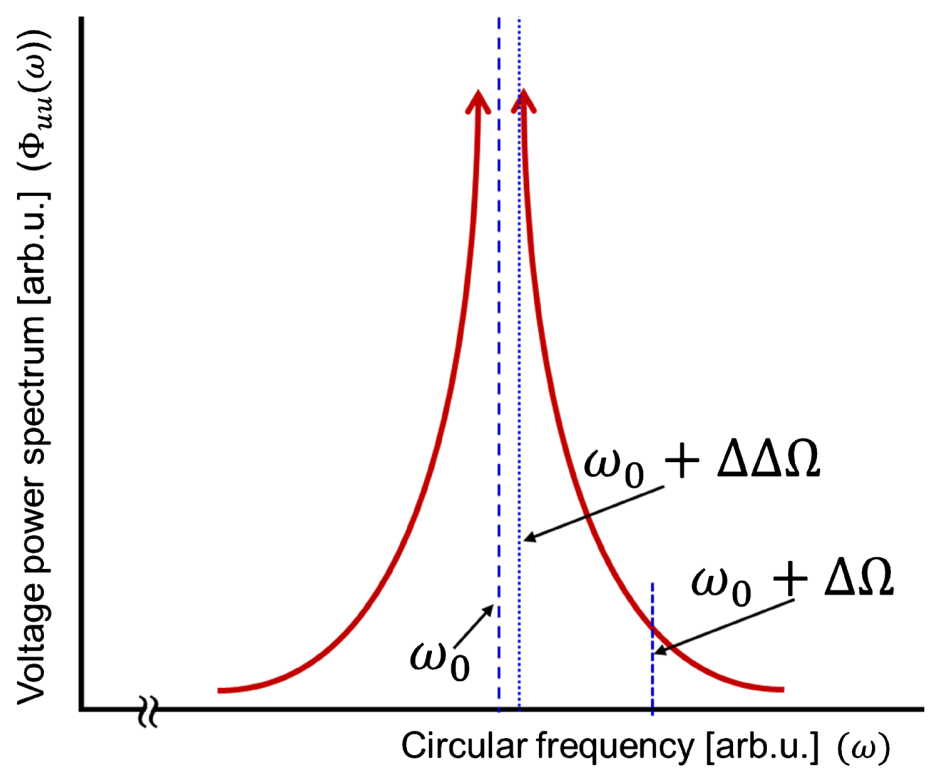

Figure 10. The power spectrum of the voltage where the distribution of the amplitude modulating noise makes a specific symmetric form.

$$
\begin{aligned}
\Delta U^{2} & =\int_{\omega}^{\omega+\Delta \Omega} R_{u u}(\Omega) \mathrm{d} \Omega \\
& =\int_{\omega+\Delta \Delta \Omega}^{\omega+\Delta \Omega}\left(U_{0}^{2} \delta(\omega-\Omega)+\frac{m^{2} U_{0}^{2}}{4} \frac{1}{|\omega-\Omega|}\right) \mathrm{d} \Omega \\
& =U_{0}^{2}+\frac{m^{2} U_{0}^{2}}{4} \ln \frac{\Delta \Omega}{\Delta \Delta \Omega}
\end{aligned}
$$

The second term of (44) shows that the square of the voltage amplitude can be extremely large near the carrier frequency, where the term tends to be infinite when $\Delta \Delta \Omega \rightarrow 0$. It follows that the average potential:

$$
\Delta U_{e e}:=\sqrt{\Delta U^{2}}=\sqrt{U_{0}^{2}+\frac{m^{2} U_{0}^{2}}{4} \ln \frac{\Delta \Omega}{\Delta \Delta \Omega}}
$$

And the field strength is represented as:

$$
\Delta E_{\text {eff }}=\frac{\Delta U_{\text {eff }}}{d}=\frac{1}{d} \sqrt{U_{0}^{2}+\frac{m^{2} U_{0}^{2}}{4} \ln \frac{\Delta \Omega}{\Delta \Delta \Omega}}
$$

where $d$ is the distance between the electrodes. Of course, arbitrarily high performance cannot be physically realized. In practice, due to fast Fourier transformation, only a point spectrum is realized. Nevertheless, the field strength amplitude can be large enough, and so the modulation does not demand a high power for appropriate effect. In conclusion, the modulation effect transmits the low-frequency power spectrum of the pink noise near the $13.56 \mathrm{MHz}$ carrier, highly efficiently, and forms two sidebands. The modulation results in very high amplitude field strength peaks near the carrier frequency.

\subsection{Modulation for Adherent Bonds}

The E-cadherin- $\beta$-catenin complex plays a crucial role in cellular adhesion [128]. 
The suppression of E-cadherin expression leads to dysfunction in cell-cell adhesion, which can cause local invasion following tumor development [53]. Loss of adhesion has been associated with increased invasiveness and metastasis of tumors [129]. On the other hand, the appropriate expression of E-cadherins has a vital role in tumor suppression [130]. The changes in cadherin expression may affect signal transduction leading to the cancer cells growing uncontrollably [131]. This challenge also appears in the bioelectric considerations [132] of cancer development. The junctions as intercellular connections, exchanging molecules in the same was as cadherins exchange molecules [133]. Importantly the adhesive connections have a vital role in tissue repairing [134].

Together with the collective and individual states, a third entity exists too: the pluripotent embryonic resting state $(\delta)$, stem cells that adapt themselves to their actual micro-environment [135]. Healthy cells are in a communicative network, maintaining the complexity of a well-controlled system, but the $\delta$ cells could form malignant transformations [133]. The malignant cells are mostly autonomic, having lost their "social" connections with other cells, and fighting for nutrients with every other cell, irrespective of their health status. The network state categorizes cells as connected or non-connected [136]. The non-connected cells also have a network but not by cell-cell bonds. The connections are formed by clusters of fighting cells trying to trigger the healthy neighbors to supply them (forced angiogenesis) [137].

The collective activity of cells emits pink noise, which is the noise of selforganization, and so it is the noise originated from the function of homeostasis. The essence of the pink noise of homeostasis is that the function of the organ-specific networked cells is regulated actively in their energy exchange in the harmony of the complex surveillance. Consequently, the variance of physiological signals remains constant over time.

The glycocalyx shell and cell membrane of a cancer cell are also different from those of a healthy cell. Because of this, the movement of proteins in the cell membrane by lateral diffusion is also more limited. Adherents are particular protein formulas that can move in the cell membrane by lateral diffusion. Contact between two cells can occur when two such proteins meet and chemically bond with each other by lateral diffusion Figure 11. The re-established intercellular connections following mEHT have been were experimentally demonstrated [107] [138].

The glycocalyx shell of cancer cells is known to be charged highly negatively. This results in repulsion, so the attraction, which is one of the preconditions for cell recognition and the start of the adhesion process, cannot prevail. Consequently, the bond-formation is hampered by the strong negative charge of the cancer cell glycocalyx shell, so the formation of intercellular bonds and networking in malignancy is unlikely.

The condition for the formation of cellular collectivity is that the cell must be fixed with adherent bonds and junctions, which is largely missing in malignant 
tumors. The modulation/demodulation stochastic resonance of noise contains signals of very high amplitude, forcing the cell clusters to intercellular bonding, manifested in communication between cells, forming functional collectivity. The self-organizing signal transformed around a carrier produces large fields. The formed gradient promotes the adhesion bonding of neighboring cells. The pinknoise modulated electric field with a very high field strength which the amplitude is transformed near $13.56 \mathrm{MHz}$, helps build the bonds of adherent proteins Figure 12.

The pink noise modulation transformed around $13.56 \mathrm{MHz}$ creates a field strength gradient towards the cell contact site. Attraction by a gradient of field strength towards the point of contact occurs between the cells. Proteins are normally dipolar with polarization vector $\boldsymbol{p}$. Therefore, a cataphoretic force $\boldsymbol{F}=(\boldsymbol{p} \nabla) \boldsymbol{E}$ acts to move the proteins toward the point of contact. The gradient

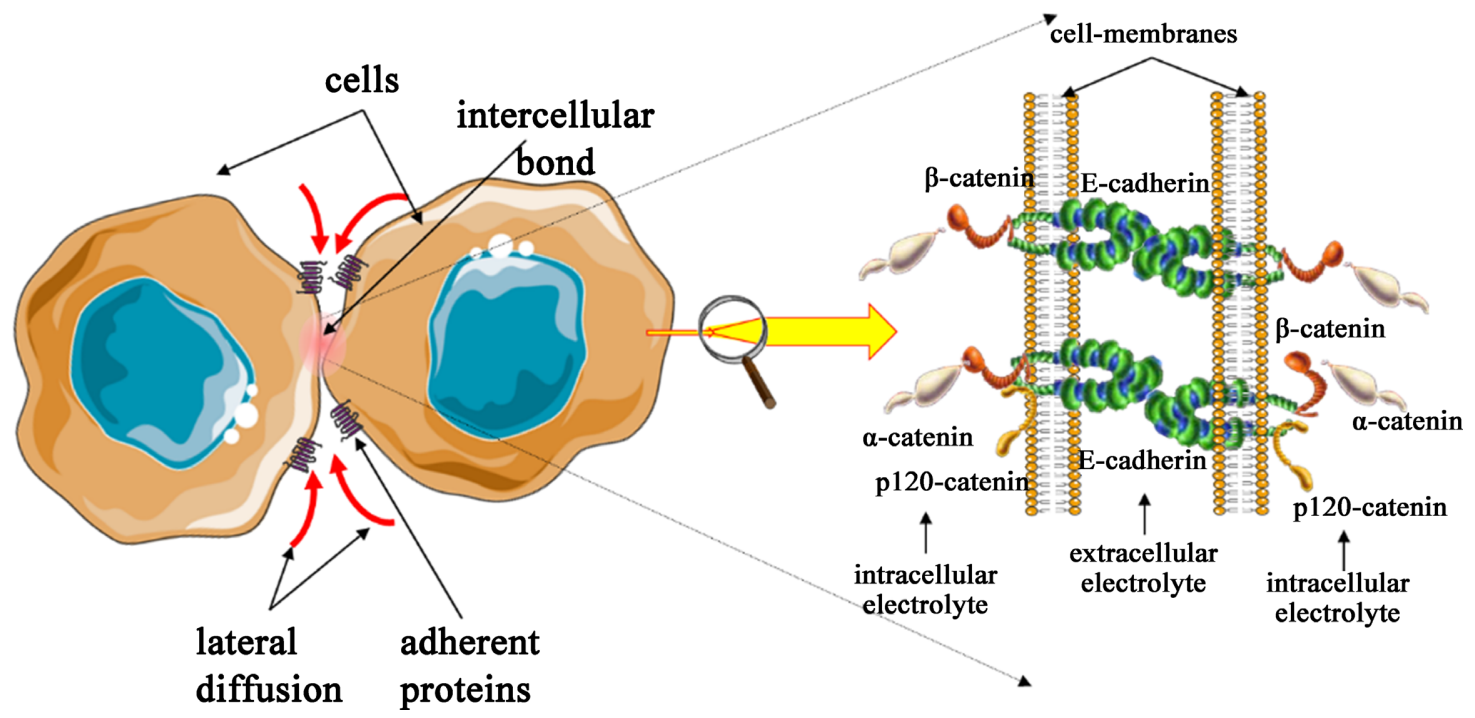

Figure 11. The movement of adherent proteins in the cell membrane promotes the reconnection of broken E-cadherin intercellular bonds.

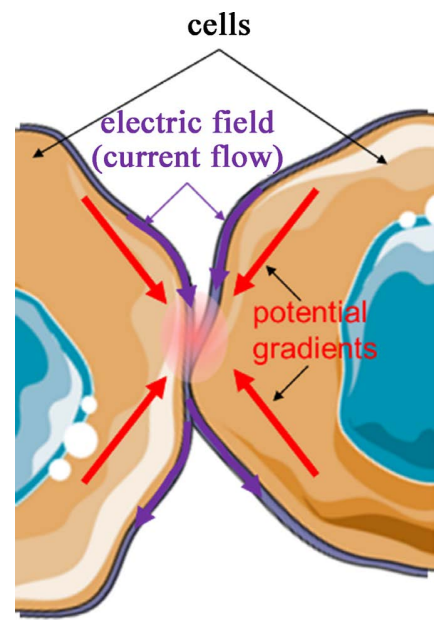

Figure 12. Evolution of field strength for two contact cells. The sizeable potential gradient actively promotes cellular contacts. 
generates a high cataphoretic force Figure 13 which promotes the contact of the cells. The process increases the likelihood of forming intercellular bonding by the connection of adherent proteins.

Due to the increased temperature in the contact point, the barrier between the protein electronic states could be easier overcome, so the moderate temperature helps the bonding. So it is expected that the thermal effect of mEHT helps the process. However, when the temperature is high, the break of bonds is more likely.

\subsection{Modulation for HSP}

The heat-shock proteins (HSPs) are chaperons to help in stabilizing the dynamic equilibrium of the cells. They are named according to their molecular weight. The first observations have connected these proteins to the heat-stress [139], but later their expression for many other stresses was discovered [140] and intensive research into their role in health and diseases began [141]. The extreme stress effect promote HSP translocation to the cellular membrane [142] and liberation to the extracellular matrix. The HSP70 has dual function [143]: inside the cell protects it (chaperone function) and outside it is a danger signal to trigger immune reactions [144]. This feature makes these proteins possible therapeutic targets in various diseases [145] [146], and especially in oncology [147].

We elaborate on a theory that pink noise mEHT is suitable for enhanced HSP expression in the membrane and extracellular electrolyte. There are two important arguments for triggering the effect:

1.The carrier frequency is chosen in the range of the $\beta / \delta$-dispersion, acting on lipid/protein bonds in the cell membrane.

2. The existence of high power amplitudes produced by the pink noise shifted to the carrier-frequency location.

The selection ensures that we excite the intended targeted cells with the high power pink-noise fluctuation near the carrier frequency. The RF-current density is increased at the cell membrane due to the $\beta / \delta$-dispersion. The carrier would shift the pink noise into the $\beta / \delta$-dispersion range, and there we expose the membrane to the pink noise. Streamlines pass from one cell to another at the points of contact of the cells. Electric fields with very high field strengths and gradients are generated in these places Figure 14.

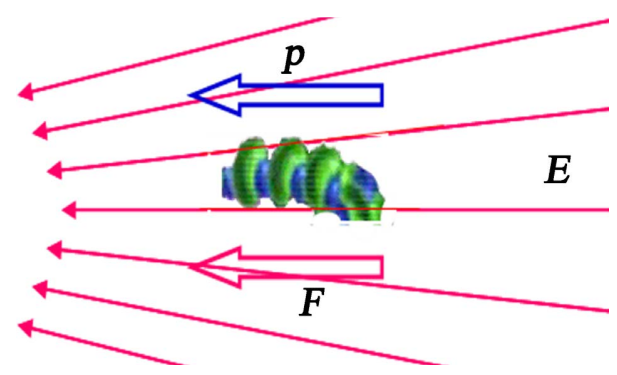

Figure 13. Formation of cataphoretic force. The inhomogeneous electric field turns the proteins in extracellular electrolyte. 
large specific absorption rate (SAR)

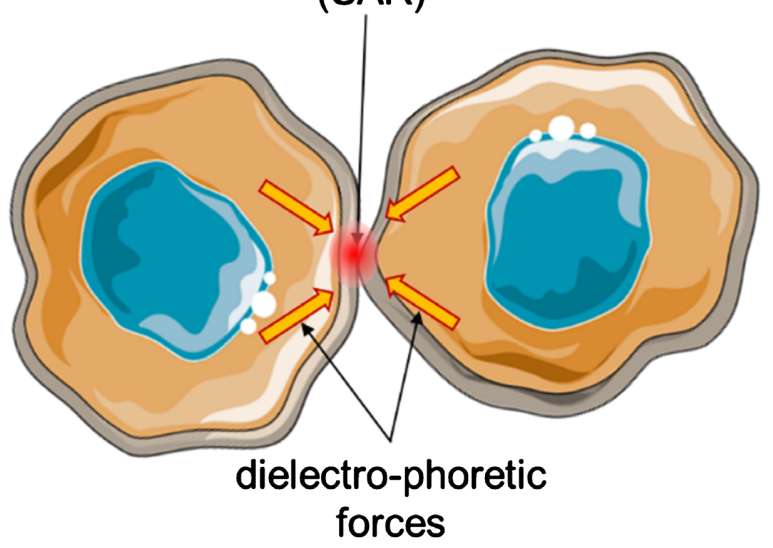

Figure 14. The field gradients are shown in Figure 12 promote the dielectric forces and induces large SAR at the contact point and reconnects the transmembrane proteins as well as provides mild heating for the cells [94] [148].

The connection points have high local SAR. However, due to the high field strength gradient enhanced by pink noise, a dielectrophoretic force also occurs, which moves half of this high SAR location to the micro-domains of the membrane thermo-sensor. The micro-domains are exposed to increased stress due to high power amplitudes. On the one hand, the stress effect is heat stress due to the high SAR and, on the other hand, mechanical deformation stress due to the high field strength gradient.

The $\beta / \delta$-dispersion is used to produce HSP, and the selected target triggers the production of HSP70 for immune stimuli [149]. The immunomodulation of extracellular HSP70 makes it a promising candidate for vaccination of cancerous diseases by presenting malignant cells' antigens [150]. The danger signal of extracellular HSP is an essential mediator for intercellular signaling and transport [151]. The molecule is part of the damage-associated molecular patternformed by immunogenic cell death, making a perfect way to produce CD8+ killer T-cells for a systemic fight against cancer.

\subsection{Modulation for Cellular Communication}

The biological transformation of normal $(\beta)$ to cancerous $(\alpha)$ is a communication phase transition which is explained on the level of individual cells [136]. The starting point of Szent-Gyorgyi is an etiological approach: the disappearance of cellular collectivity [53]. The $\beta \rightarrow \alpha$ state change driven by changes of the micro-environment of the malignant cells [4].

The division naturally needs higher energy income than the regular life of the cells. The cytoskeleton polymerization during the cell division breaks the networking connections, allowing the free formation of the new cytoskeleton and intensifying support of the microenvironment of the dividing cells by higher diffusion in the free electrolyte. After finishing the division, the cells are reconnected, the network control activates again. The internal energy resources pro- 
mote the appropriate, satisfactory amount of energy. Together with the environmental sources, the cells build up the daughter cells with the healthy cellular division [152]. However, the malignant cells have no reserves for the extreme energy demand to proliferate [153]. The usual healthy process does not work in malignant proliferation. The tumor cells do not return to the network. They remain as individuals and continue the proliferation. One explanation concentrates on the dielectric changes in the cell microenvironment [154], which is high in the cancerous process in vivid form [155]. Noisy communication can also cause cancer. This can occur when the relative arrangement of the cells does not allow for an interaction leading to cyclic symmetry, like requested [34]. From our perspective, this can be interpreted, meaning that if the symmetry is not cyclic, it is divisible. Otherwise, it is not, which supports the idea, that the cellular position has a vital role in favoring the malignant proliferation [156].

\section{Discussion-Cancer Therapy}

The strategy to eliminate the cancerous processes focuses on the weakest point of the tumor: individualism. The missing overall network makes them vulnerable, as they are alone in fighting the stress.

The malignant development misses the healthy homeostatic regulation. The systemic controls do not work. Their extreme energy demand drives their systemic effect. The cancerous process concentrates on intensive proliferation and uses healthy hosts to support it. This complex process misleads the healthy host, presenting their actions as normal energy-demand for healing the lesion like a wound (as was described shown 25 years ago [88]). Cancer presents itself as trying to heat, and the system cannot recognize the "cheating" due to the hidden identification signs. This shows that the entire malignant process is essentially a wound repair process [157]. The idea has been investigated more recently, with comparisons between the hallmarks of the two processes [158], demonstrating the role of this mechanism in the formation of metastases [159]. The bio-system falsely recognizes the tumor-like wound [160] and stimulates its environment to heal the irregularity (meaning to produce cells to heal).

The permanent reparation demand depletes the available stem cells, [161] [162], and is emphasizes a different repair pathway: the proto-oncogenes are activated, and malignant transformation could happen, inducing the clinical manifestation of cancer [163]. The malignant transformation of the wound results in the secretion of proto-oncogenes [164] [165] [166], and intensive capture and stimulation of the stem-cells from other places [167] [168].

Ignoring the healthy regulations and the collectivity of the host tissue has some structural and temporal signs to recognize it. The structure of the individual cells is more disordered than the networked healthy tissue, and the intensive individual metabolic demand changes the structure of extracellular electrolyte. The permanent cellular division periodically collapses the cell's actual cytoskeleton and builds up new ones again, decomposed by the subsequent fission and 
repolymerization. This changes the cellular form individually, and the active dynamism, which differs from the healthy regulated one, is expressed in the noise of the tumor processes. The noisy difference is measurable by electric impedance [169], detecting the "color" of the noise. As shown above, the "color" is determined by the self-similarity scaling exponent of power density by frequency. The measured exponent decreases from the near-1 (pink noise), depending on the weakened cellular interactions, and so the autonomy is field. The same change was observed in the autocorrelation [170], lowering the function value at $1 / \mathrm{e}$, so the correlation was decreasing, which characterizes the trend towards autonomy. The weakness of the malignant process is this autonomy when the cells are alone to fight against any external stresses. So the weakness, which we have to use [171], is the missing network, the missing collective harmony. The individualism of the cells is similar to atavistic reverse development in the evolutionary meaning. The atavistic model could be used as a starting point, but this model does not consider all the crucial details (hallmarks) that keep the single-celled units of cancer development alive [172]. The wound healing support of the host tissue is missing from the atavistic model, and so it is not applicable. However, the proper noise application places the theranostic key in the hand of the therapist. The noise spectrum is measurable for diagnosis [171], and the pink noise as a homeostatic harmony character could make a forceful selected harmonization factor, which harmonizes the precancerous cells, rebinding their broken intercellular connections [107] [173], forcing back the healthy order. When the rebinding is impossible, the harmonizing force "softly" destroys the cells, exposing their genetic content for antigen presentation, and igniting the normal immune reaction against the malignancy. In other words, the mask falls off.

The practice of modulated electromagnetic applications connects the knowledge of hyperthermia with electromagnetic effects. The modulated electro-hyperthermia (mEHT, trade name oncothermia ${ }^{\oplus}$ ) has used this method for years in a broad application for various tumors. Below we summarize the most crucial information-set about its processes and results, showing publications.

Numerous practical applications proved the feasibility of the mEHT treatments. Based on some principal considerations, the method uses the thermal and non-thermal effects [116] in a synergy. The non-thermal effects are connected to the cellular membranes [114] [115], emphasizing the physical potential of the amplitude modulation [174]. The strong connection between the thermal-factors and electric effects involves the similarities between their actions [175], and the strong synergy was indeed observed in vivo [176]. The absorbed power develops the temperature [177] which has a selective heating possibility [178] by electric inhomogeneities and depends on the technical solution of the coupling [179].

The temperature development is a complex process [180], and connected to the dosing in treatment practice [181] [182]. 
The extracellular action complexly interconnects the electric field with the thermal effects [183]. The thermal noise influences the electric field effect [22] [184], but it does not block the intracellular processes [185]. The modulation technology has been described in oncology [186].

The RF energy is predominantly absorbed on the clustered transmembrane proteins (rafts) [94], exciting their receptors [94] [187] [188]. The excitation damages the malignant cells dominantly in an apoptotic way [105] [149]. The mEHT promoted extracellular HSP70 supports the apoptotic processes [108]. The membrane rafts are the key elements of energy absorption [189], which is an energy intake in the nano-range [148]. The whole mEHT process is immunogenic [190]. The method may be applied complementary to radiotherapy [191] [192]; an example is the resensitization of the radioresistant pancreatic cells for further treatment [193]. The complementary application of mEHT with chemotherapy has also been successful [194] [195].

A recent review summarizes the molecular biology background of the tumor damage mechanisms revealed in cancer models [196].

In the clinical application, the safety of the method was investigated in one of the most sensitive organs, the brain. The prospective safety study involved the dose-expansion for non-invasive transcranial therapy in $3^{\text {rd }}$ and $4^{\text {th }}$ line, advanced; relapsed high-grade gliomas and proved the safety even in the daily applications [197]. Efficacy studies validated the feasibility of this method for such a short survival, high-mortality stage of the disease, [198] [199] [200]. The special safety [201] and efficacy [202] studies in advanced non-small cell lung cancer patients justified the use of mEHT in this type of malignancy as well. The analyses of brain [203] and lung [204] studies support the economic advantage of mEHT. The applications in gastrointestinal tracts like colon, [205], rectum [206], liver [207], and pancreas [208] [209] demonstrated the versatile functions of the mEHT method. The relapsed, refractory, or progressive heavily treated ovarian cancer [210], and the advanced, recurrent cervix uteri [211] [212] were also successfully treated with complementary combinations of conventional chemoradiotherapy and mEHT, obtaining low toxicity and longer survival, with improved quality of life [213]. The applicability for sarcomas in complementary therapy protocols was also proven [214] [215]. The immunogenic influence in combination with other immune supports is also remarkable [216] and realizes tumor-specific immune reactions for distant metastases (abscopal effect) [217] [218]. These observations orient the treatment to tumor-directed immunotherapy [219] and could be a basis of the personalized medicine [220]. Remarkable application of mEHT for the peritoneal carcinomatosis with malignant ascites, [221], which extends the study focus to ascites cases.

Recently a review had summarized the clinical evidence of mEHT for the practicing oncologists [222], and an application guideline was published by an international collective [223].

Notably, most studies have single-arm protocols, which have inherent com- 
plications in evaluating the mEHT method. The patients involved in these studies are in relapsed advanced stages when the conventional therapies are limited or have failed. Collecting a cohort for reference at this stage is exceptionally challenging and, in most cases, impossible [224]. However, the evaluation of single-arm trials has specialties, which could improve the level of evidence of the results. The simplest one is the comparison of the single-arm results from different studies with the same protocol. For example, the comparison of advanced glioblastoma (Figure 15) [225] [226] [227] [200] [203], and pancreas (Figure 16) [228] [229] [225] [230] [231], studies shows the significant difference of the common median from the historical or database control.

Other analysis of single-arm results uses the self-similarity of living processes [232] [233], building up the reference arm from the parameters of the active single-arm [234] [235].

\section{Conclusion}

The modulation of radiofrequency carriers causes stochastic resonances, which act mainly on enzymatic processes. The demodulation is also effectively performed by stochastic resonance, which allows the low-frequency modulation information to be delivered selectively to the cancerous cells. There are as many resonant frequencies as there are enzymatic reactions that exist.

The modulation intensively changes the paradigm of cancer treatment. It boosts the healthy network and selectively destroys the malignant cells. The cell-killing process is immunogenic, allowing for the release of genetic information

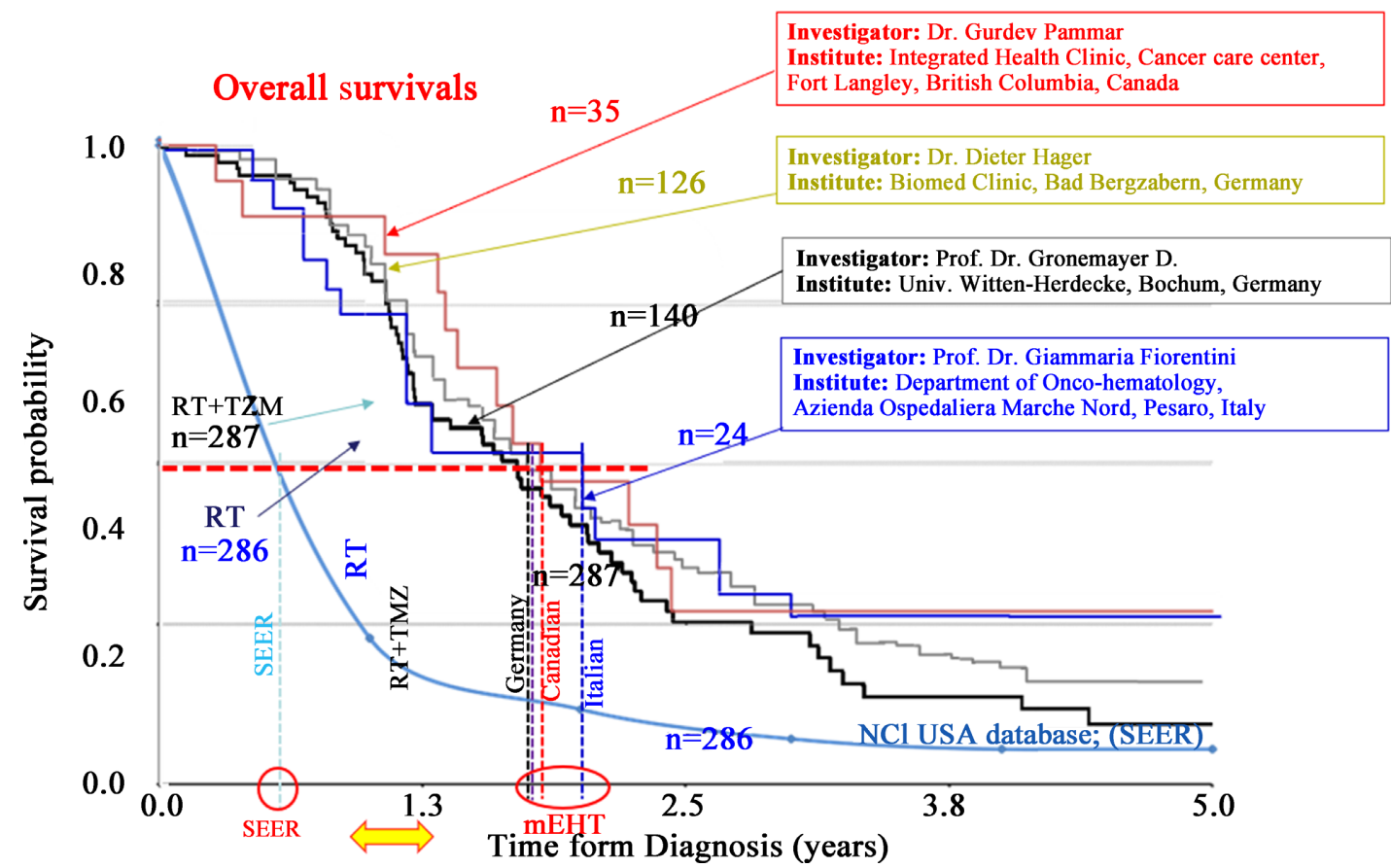

Figure 15. The comparison of the single-arm mEHT studies with the database results for advanced, relapsed glioblastoma multiform. The different groups with different studies based on the same mEHT protocol well correspond with each other and significantly differ from the database. 


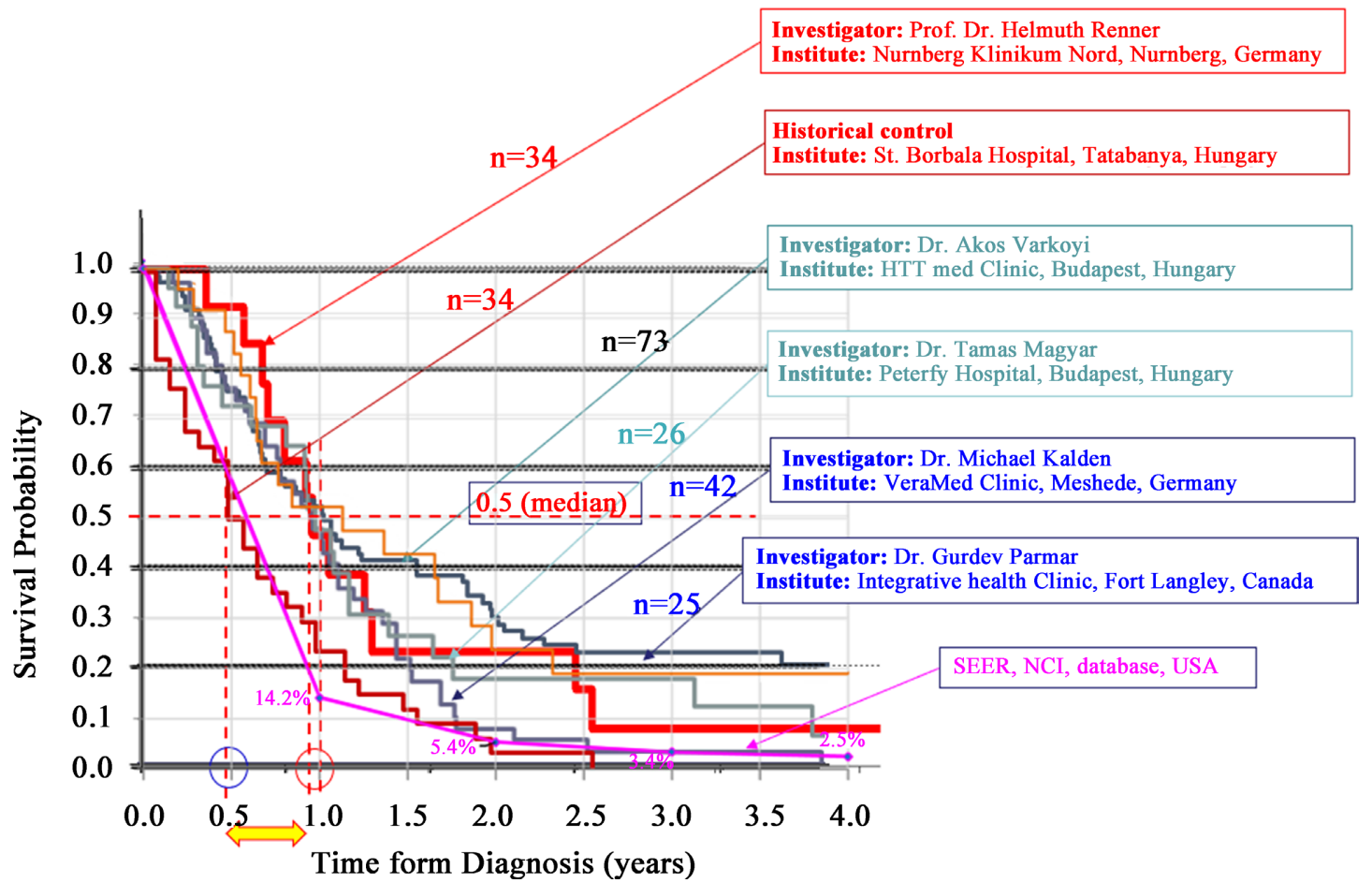

Figure 16. The comparison of the single-arm mEHT studies with the database results for advanced, relapsed inoperable pancreas carcinoma. The database results and the historical arm for the same stage pancreas survivals correspond each other. The different groups with different studies based on the same mEHT protocol well correspond with each other and significantly differ from the database and the historical arm.

in a molecular pattern (DAMP), which could form antigen presenting cells and develop tumor-specific immune reactions. The modulated signal is a complex mixture of non-thermal electron excitation for chemical reactions, and thermal boosting of the enzymatic reactions.

The complex homeostatic network has a cyclic symmetry which controls the balance and the apoptotic processes. The living cellular structures are open to the effects of energy, requiring energy input, followed by the output of waste. This organized transport system is not possible without direct cellular communication (no "social signal"). The cyclic topological order makes the noiseless inter- and intra-cellular communications possible despite the thermal noise background.

The malignant transformation breaks the organized transport system and seeks to build up new structures for the new demands. However, there are fundamental differences: the healthy construction is driven by the collective signal and seeks to optimize the energy-use for highest efficacy, while the malignant construction is only driven by the topology and physics of the mass number of individual, competing cells, irrespective of the efficacy of the energy conversion. The new structure modifies the cell-cell communications and arranges the malignant cellular microenvironment suitable for the autonomic actions. The topology in this meaning has significant diagnostic (pathologic) meaning: the more the pattern of tumor (networking "mesh" and form of the cells) resembles 
the healthy cells, the less malignant the tumor is.

The modulation affects the malignant construction in various ways:

1) boosts the healthy network;

2) limits the autonomy of the cells;

3) selects the malignant cells and targets them with resonance energy-absorption;

4) excites selected molecules, influencing and promoting the enzymatic processes;

5) supports the immune system and triggers selective antitumor effects;

6) regenerates the lost intercellular adherent bonds, and with this limits the invasion of the malignant cells;

7) frees the HSP70 extracellularly to carry genetic information about the malignant cell to antigen-presenting cells;

8) supports the cellular communications and the synchrony of the cells.

The modulation signal is a time-fractal representing the systemic homeostatic fluctuations. It is self-similar, having $1 / f$ noise of the power density. It might promote the-establishing the lost cellular communications or stimulate apoptosis of the cells which remain individual.

The modulation principles to support the healthy processes have broad feasibility to treat the patients. The therapy is a complex, multi-component clinical process, where one of the factors is the modulated electro-hyperthermia (mEHT). The mEHT has proved its exceptional capability to treat late-stage, relapsed cancerous tumors, complementary to any other conventional therapies. In instances where there are no further treatment options available, mEHT could be applied as monotherapy, or in some cases, could desensitize tumors to the previously ineffective conventional treatment.

\section{Acknowledgments}

This work was supported by the Hungarian National Research Development and Innovation Office PIACI KFI grant: 2019-1.1.1-PIACI-KFI-2019-00011.

\section{Conflicts of Interest}

The author declares no conflicts of interest regarding the publication of this paper.

\section{References}

[1] Trigos, A.S., Pearson, R.B., Papenfuss, A.T., et al. (2016) Altered Interactions between Unicellular and Multicellular Genes Drive Hallmarks of Transformation in a Diverse Range of Solid Tumors. PNAS, 114, 6406-6411. https://doi.org/10.1073/pnas.1617743114

[2] Davidson, C.D., Wang, W.Y., Zaimi, I., et al. (2019) Cell Force-Mediated Matrix Reorganization Underlies Multicellular Network Assembly. Scientific Reports, 9, Article No. 12. https://doi.org/10.1038/s41598-018-37044-1

[3] Balmain, A., Gray, J. and Ponder, B. (2014) The Genetics and Genomics of Cancer. Nature Genetics Supplement, 33, 238-244. https://doi.org/10.1038/ng1107

[4] Szigeti, G.P., Szasz, O. and Hegyi, G. (2017) Connections between Warburg's and 
Szentgyorgyi's Approach about the Causes of Cancer. Journal of Neoplasm, 1, 1-13.

[5] Hanahan, D. and Weinberg, R.A. (2000) The Hallmarks of Cancer. Cell, 100, 57-70. https://doi.org/10.1016/S0092-8674(00)81683-9

[6] Hanahan, D. and Weinberg, R.A. (2011) Hallmarks of Cancer: The Next Generation. Cell, 144, 646-674. https://doi.org/10.1016/j.cell.2011.02.013

[7] Dyas, F.G. (1928) Chronic Irritation as a Cause of Cancer. JAMA, 90, 457. https://doi.org/10.1001/jama.1928.92690330003008c

[8] Dvorak, H.F. (1986) Tumors: Wounds That Do Not Heal, Similarities between Tumor Stroma Generation and Wound Healing. The New England Journal of Medicine, 315, 1650-1659. https://doi.org/10.1056/NEJM198612253152606

[9] Platz, E.A. and Marzo, A.M. (2004) Epidemiology of Inflammation and Prostate Cancer. The Journal of Urology, 171, S36-S40.

https://doi.org/10.1097/01.ju.0000108131.43160.77

[10] Punyiczki, M. and Fesus, L. (1998) Heat Shock and Apoptosis: The Two Defense Systems of the Organisms May Have Overlapping Molecular Elements. Annals of the New York Academy of Sciences, 951, 67-74. https://doi.org/10.1111/j.1749-6632.1998.tb08978.x

[11] Aktipis, C.A., Bobby, A.M., Jansen, G., et al. (2015) Cancer across the Tree of Life: Cooperation and Cheating in Multicellularity. Philosophical Transactions of the Royal Society B, 370, Article ID: 20140219. https://doi.org/10.1098/rstb.2014.0219

[12] Varma, R. and Selman, J.S., (1991) Techniques for Characterisation of Electrodes and Electrochemical Processes. John Wiley \& Sons, New York.

[13] Jacobsen, T. and West, K. (1995) Diffusion Impedance for Planar, Cylindrical, and Spherical Geometry. Electrochimica Acta, 40, 255-262.

https://doi.org/10.1016/0013-4686(94)E0192-3

[14] Robinson, F.N.H. (1962) Noise in Electrical Circuits. Oxford Univ. Press, London.

[15] Goldup, A., Ohki, S. and Danielli, J.F. (1970) Black Lipid Films. Recent Progress in Surface Science, 3, 193-261. https://doi.org/10.1016/B978-0-12-571803-5.50013-4

[16] Goldman, D.E. (1943) Potential, Impedance, and Rectification in Membranes. Journal of General Physiology, 27, 37-60. https://doi.org/10.1085/jgp.27.1.37

[17] Ramachandran, S., Blick, R.H. and van der Weide, D.W. (2010) Radio-Frequency Rectification on Membrane Bound Pores. Nanotechnology, 1, 75201. https://doi.org/10.1088/0957-4484/21/7/075201

[18] Tanaka, A. and Tokimasa, T. (1999) Theoretical Background for Inward Rectification. Tokai Journal of Experimental and Clinical Medicine, 24, 147-153.

[19] Szendro, P., Vincze, G. and Szasz, A. (2001) Bio-Response to White Noise Excitation. Electro- and Magnetobiology, 20, 215-229.

https://doi.org/10.1081/JBC-100104145

[20] Kerr, W.T., Anderson, A., Lau, E.P., et al. (2012) Automated Diagnosis of Epilepsy Using EEG Power Spectrum. Epilepsia, 53, e189-e192.

[21] Dave, K., Davtyan, A., Papoian, G.A., et al. (2015) Environmental Fluctuations and Stochastic Resonance in Protein Folding. ChemPhysChem, 17, 1341-1348. https://doi.org/10.1002/cphc.201501041

[22] Astumian, R.D., Weaver, J.C. and Adair, R.K. (1995) Rectification and Signal Averaging of Weak Electric Fields by Biological Cells. Proceedings of the National Academy of Sciences of the United States of America, 92, 3740-3743. https://doi.org/10.1073/pnas.92.9.3740 
[23] Vincze, Gy., Szasz, A. and Szasz, N. (2005) On the Thermal Noise Limit of Cellular Membranes. Bioelectromagnetics, 26, 28-35. https://doi.org/10.1002/bem.20051

[24] Winfree, A.T. (1984) The Prehistory of the Belousov-Zhabotinsky Oscillator. Journal of Chemical Education, 61, 661-663. https://doi.org/10.1021/ed061p661

[25] Hudson, J.L. and Mankin, J.C. (1981) Chaos in the Belousov-Zhabotinskii Reaction. The Journal of Chemical Physics, 74, 6171-6177. https://doi.org/10.1063/1.441007

[26] Matsumoto, K. and Tsuda, I. (1983) Noise-Induced Order. Journal of Statistical Physics, 31, 87-106. https://doi.org/10.1007/BF01010923

[27] Taylor, A.F., Tinsley, M.R., Wang, F., et al. (2009) Dynamical Quorum Sensing and Synchronization in Large Populations of Chemical Oscillators. Science, 323, 614-617. https://doi.org/10.1126/science.1166253

[28] Hunt, T. and Schooler, J.W. (2019) The Easy Part of the Hard Problem: A Resonance Theory of Consciousness. Frontiers in Human Neuroscience, 13, Article No. 378. https://doi.org/10.3389/fnhum.2019.00378

[29] Voss, R.F. and Clarke, J. (1975) "1/f Noise" in Music and Speech, Nature, 28, 317-318. https://doi.org/10.1038/258317a0

[30] Colley, I.D. and Dean, R.T. (2019) Origins of 1/f Noise in Human Music Performance from Short-Range Autocorrelations Related to Rhythmic Structures. PLoS ONE, 1, e0216088. https://doi.org/10.1371/journal.pone.0216088

[31] Chorvatova, A. and Chorvat Jr., D. (2011) Coherent Resonant Properties of Cardiac Cells. In: Min, M., Ed., Cardiac Pacemakers-Biological Aspects, Clinical Applications and Possible Complications, IntechOpen, London, 25-45. https://doi.org/10.5772/23292

[32] Schrödinger, E. (1951) Science and Humanism. Cambridge University Press, Cambridge.

[33] Raff, M.C. (1992) Social Controls on Cell Survival and Death. Nature, 356, 397-400. https://doi.org/10.1038/356397a0

[34] Von Neumann, J. (1959) The Computer and the Brain. Yale University Press, London.

[35] Szendro, P., Vincze, G. and Szasz, A. (2001) Pink Noise Behaviour of the Bio-Systems. European Biophysics Journal, 30, 227-231. https://doi.org/10.1007/s002490100143

[36] Goldenfeld, N. and Woese, C. (2010) Life Is Physics: Evolution as a Collective Phenomenon Far from Equilibrium.

[37] West, B.J. and West, D. (2011) Are Allometry and Macroevolution Related? Physica A: Statistical Mechanics and Its Applications, 390, 1733-1736.

https://doi.org/10.1016/j.physa.2010.11.031

[38] West, G.B. and Brown, J.H. (2005) The Origin of Allometric Scaling Laws in Biology from Genomes to Ecosystems: Towards a Quantitative Unifying Theory of Biological Structure and Organization. Journal of Experimental Biology, 208, 1575-1592. https://doi.org/10.1242/jeb.01589

[39] Häusser, M. (2001) Synaptic Function: Dendritic Democracy. Current Biology, 11, R10-R12. https://doi.org/10.1016/S0960-9822(00)00034-8

[40] Das, Neves, R.P., Jones, N.S. andreu, L., Gupta, R., Enver, T. and Iborra, F.J. (2010) Connecting Variability in Global Transcription Rate to Mitochondrial Variability. PLOS Biology, 8, e1000560. https://doi.org/10.1371/journal.pbio.1000560

[41] Johnston, I.G., Gaal, B., das, Neves, R.P., Enver, T., Iborra, F.J. and Jones, N.S. (2012) Mitochondrial Variability as a Source of Extrinsic Cellular Noise. PLOS Computa- 
tional Biology, 8, e1002416. https://doi.org/10.1371/journal.pcbi.1002416

[42] Alberts, B., Alexander, J., Julian, L., Martin, R., Keith, R. and Peter, W. (1994). Molecular Biology of the Cell. Garland Publishing Inc., New York.

[43] Dawkins, R. (1976) The Selfish Gene. Oxford University Press, Oxford.

[44] McAvoy, A. and Hauert, C. (2016) Autocratic Strategies for Iterated Games with Arbitrary Action Spaces. PNAS, 113, 3573-3578.

https://doi.org/10.1073/pnas.1520163113

[45] McAvoy, A. and Hauert, C. (2016) Autocratic Strategies for Alternating Games. Theoretical Population Biology, 113, 13-22. https://doi.org/10.1016/j.tpb.2016.09.004

[46] Nowak, M.A. and Sigmund, K. (1994) The Alternating Prisoner's Dilemma. Journal of Theoretical Biology, 168, 219-226. https://doi.org/10.1006/jtbi.1994.1101

[47] Ross-Gillespie, A. and Kümmerli, R. (2014) Collective Decision-Making in Microbes. Frontiers in Microbiology, 5, Article No. 54. https://doi.org/10.3389/fmicb.2014.00054

[48] Bhardway, N., Yan, K.K. and Gerstein, M.B. (2010) Analysis of Diverse Regulatory Networks in a Hierarchical Context Shows Consistent Tendencies for Collaboration in the Middle Levels. PNAS, 107, 6841-6846. https://doi.org/10.1073/pnas.0910867107

[49] Dissado, L.A. (1990) A Fractal Interpretation of the Dielectric Response of Animal Tissues. Physics in Medicine \& Biology, 35, 1487-1503. https://doi.org/10.1088/0031-9155/35/11/005

[50] El-Lakkani, A. (2001) Dielectric Response of Some Biological Tissues. Bioelectromagnetics, 22, 272-279. https://doi.org/10.1002/bem.50

[51] Chigira, M., Noda, K. and Watanabe, H. (1990) Autonomy in Tumor Cell Proliferation. Medical Hypotheses, 32, 249-254. https://doi.org/10.1016/0306-9877(90)90101-J

[52] Ngo, S., Liang, J., Su, Y.H. and O’Brien, L.E. (2020) Tumor Establishment Requires Tumor Autonomous and Non-Autonomous Deregulation of Homeostatic Feedback Control. https://doi.org/10.1101/541912

[53] Li, J., Cheng, L. and Jiang, H. (2019) Cell Shape and Intercellular Adhesion Regulate Mitotic Spindle Orientation. Molecular Biology of the Cell, 30, 2458-2468. https://doi.org/10.1091/mbc.E19-04-0227

[54] Szentgyorgyi, A. (1978) The Living State and Cancer. Marcel Dekker Inc., New York.

[55] Jeanes, A., Gottardi, C.J. and Yap, A.S. (2008) Cadherins and Cancer: How Does Cadherin Dysfunction Promote Tumor Progression? Oncogene, 27, 6920-6929. https://doi.org/10.1038/onc.2008.343

[56] Mendonsa, A.M., Na, T.Y. and Gumbiner, B.M. (2018) E-Cadherin in Contact Inhibition and Cancer. Oncogene, 37, 4769-4780.

https://doi.org/10.1038/s41388-018-0304-2

[57] Szasz, O., Szasz, A.M., Minnaar, C. and Szasz, A. (2017) Heating Preciosity-Trends in Modern Oncological Hyperthermia. Open Journal of Biophysics, 7, 116-144. https://doi.org/10.4236/ojbiphy.2017.73010

[58] Szentgyorgyi, A. (1960) Introduction to a Submolecular Biology. Academic Press, New York. https://doi.org/10.1016/B978-0-12-395612-5.50005-1

[59] Szasz, A. (1991) An Electrically Driven Instability: The Living-State (Does the Room 
Temperature Superconductivity Exist?). Physiological Chemistry and Physics and Medical NMR, 23, 43-50.

[60] Alfarouk, K.O., Shayoub, M.E.A., Muddathir, A.K., Elhassan, G.O. and Bashir, A.H.H. (2011) Evolution of Tumour Metabolism Might Reflect Carcinogenesis as a Reverse Evolution Process (Dismantling of Multicellularity). Cancers, 3, 3002-3017. https://doi.org/10.3390/cancers3033002

[61] Weinberg, R.A. (1999) One Renegade Cell. How Cancer Begins. Basic Books, New York.

[62] Szigeti, Gy.P., Szasz, A.M. and Szasz, A. (2020) The Growth of Healthy and Cancerous Tissues. Open Journal of Biophysics, 10, 113-128. https://doi.org/10.4236/ojbiphy.2020.103010

[63] Willmer, P. (2009) Environmental Physiology of Animals. Wiley, Hoboken.

[64] West, G.B., Brown, J.H. and Enquist, B.J. (1997) A General Model for the Origin of Allometric Scaling Laws in Biology. Science, 276, 122-126.

https://doi.org/10.1126/science.276.5309.122

[65] Dodds, P.S., Rothman, D.H. and Weitz, J.S. (2001) Re-Examination of the "3/4-Law" of Metabolism. Journal of Theoretical Biology, 209, 9-27. https://doi.org/10.1006/jtbi.2000.2238

[66] Rothman, D.H. and Weitz, J.S. (2005) Beyond the "3/4-Power Law": Variation in the Intra- and Interspecific Scaling of Metabolic Rate in Animals. Biological Reviews, 80, 611-662. https://doi.org/10.1017/S1464793105006834

[67] Kozlowski, J. and Konarzewski, M. (2004) Is West, Brown and Enquist's Model of Allometric Scaling Mathematically Correct and Biologically Relevant? Function Ecology, 18, 283-289. https://doi.org/10.1111/j.0269-8463.2004.00830.x

[68] Beckman, R.A. and Loeb, L.A. (2005) Genetic Instability in Cancer: Theory and Experiment. Seminars in Cancer Biology, 15, 423-435.

https://doi.org/10.1016/j.semcancer.2005.06.007

[69] Ferguson, L.R., Chen, H., Collins, A.R., Connel, M., Damia, G., Dasgupta, S., et al. (2015) Genomic Instability in Human Cancer: Molecular Insights and Opportunities for Therapeutic Attack and Prevention through Diet and Nutrition. Seminars in Cancer Biology, 35, S5-S24.

https://doi.org/10.1016/j.semcancer.2015.03.005

[70] Colotta, F., Allavena, P., Sica, A., Garlanda, C. and Mantovani, A. (2009) CancerRelated Inflammation, the Seventh Hallmark of Cancer: Links to Genetic Instability. Carcinogenesis, 30, 1073-1081. https://doi.org/10.1093/carcin/bgp127

[71] Luoto, K.R., Kumareswaran, R. and Bristow, R.G. (2013) Tumor Hypoxia as a Driving Force in Genetic Instability. Genome Integrity, 4, 5.

https://doi.org/10.1186/2041-9414-4-5

[72] Loewenstein, W.R. (1999) The Touchstone of Life, Molecular Information, Cell Communication and the Foundations of the Life. Oxford University Press, Oxford, New York, 298-304.

[73] Szasz, O. (2020) Ch. 11. Local Treatment with Systemic Effect: Abscopal Outcome. In: Szasz, A., Ed., Challenges and Solutions of Oncological Hyperthermia, Cambridge Scholars Publishing, Newcastle upon Tyne District, Publishing, Newcastle upon Tyne District, 192-205.

[74] Schwan, H.P. and Takashima, S. (1991) Dielectric Behavior of Biological Cells and Membranes. Bulletin of the Institute for Chemical Research, Kyoto University, 69, 459-475. 
[75] Cole, K.S. (1972) Membranes, Ions and Impulses. University of California Press, Berkeley.

[76] Anderson, J.C. (1964) Dielectrics, Chapman \& Hall, London.

[77] Pethig, R.R. (1979) Dielectric and Electronic Properties of Biological Materials. Wiley, Hoboken.

[78] Schwan, H.P. (1957) Electrical Properties of Tissue and Cell Suspensions. Advances in Biological and Medical Physics, 5, 147. https://doi.org/10.1016/B978-1-4832-3111-2.50008-0

[79] Martinsen, O.G., Grimnes, S. and Mirtaheri, P. (2000) Non-Invasive Measurements of Post Mortem Changes in Dielectric Properties of Haddock Muscle-A Pilot Study. Journal of Food Engineering, 43, 189-192. https://doi.org/10.1016/S0260-8774(99)00151-X

[80] Grant, E.H., Sheppard, R.J. and South, S.P. (1978) Dielectric Behavior of Biological Molecules in Solution. Clarendon Press, Oxford.

[81] Schwarz, G. and Seelig, J. (1968) Kinetic Properties and the Electric Field Effect of Life Helix-Coil Transition of Poly(y-benzyl L-glutamate) Determined from Dielectric Relaxation Measurements. Biopolymers, 6, 1263-1277. https://doi.org/10.1002/bip.1968.360060904

[82] Debye, F. (1928) Dispersion of the Conductivity and Dielectric Constants of Strong Electrolytes. Physikalische Zeitschrift, 29, 121-401.

[83] Pennock, B.E. and Schwan, H.P. (1969) Further Observations on the Electrical Properties of Hemoglobin Bound Water. The Journal of Physical Chemistry, 73, 2600-2610. https://doi.org/10.1021/j100842a024

[84] Kirkwood, J.G. and Shumaker (1952) Forces between Protein Molecules in Solution Arising from Fluctuations in Proton Charge and Configuration. Proceedings of the National Academy of Sciences of the United States of America, 38, 863-871. https://doi.org/10.1073/pnas.38.10.863

[85] South, G.P. and Grant, E.H. (1972) Dielectric Dispersion and Dipole Moment of Myoglobin in Water. Proceedings of the Royal Society A, 328, 371.

https://doi.org/10.1098/rspa.1972.0083

[86] Pethig, R.R. (2017) Dielectrophoresis: Theory, Methodology and Biological Applications. John Wiley \& Sons, Hoboken. https://doi.org/10.1002/9781118671443

[87] Asami, K. (2002) Characterization of Biological Cells by Dielectric Spectroscopy. Journal of Non-Crystalline Solids, 305, 268-277. https://doi.org/10.1016/S0022-3093(02)01110-9

[88] Pauly, H. and Schwan, H.P. (1959) Uber die Impedanzeiner Suspension von Kugelformigen Teilchenmiteiner Schale. Zeitschrift für Naturforschung B, 14, 125-131. https://doi.org/10.1515/znb-1959-0213

[89] Stoy, R.D., Foster, K.R. and Schwan, H.P. (1982) Dielectric Properties of Mammalian Tissues from 0.1 to $100 \mathrm{MHz}$ : A Summary of Recent Data. Physics in Medicine \& Biology, 27, 501-513. https://doi.org/10.1088/0031-9155/27/4/002

[90] Gotz, M., Karsch, L. and Pawelke, J. (2017) A New Model for Volume Recombination in Plane-Parallel Chambers in Pulsed Fields of High Dose-per-Pulse. Physics in Medicine \& Biology, 62, 8634-8654. https://doi.org/10.1088/1361-6560/aa8985

[91] Pethig, R. (1984) Dielectric Properties of Biological Materials: Biophysical and Medical Application. IEEE Transactions on Electrical Insulation, E1-19, 453-474. https://doi.org/10.1109/TEI.1984.298769 
[92] Schwan, H.P. (1963) Determination of Biological Impedances. In: Physical Techniques in Biological Research, Vol. 6, Academic Press, New York, 323-406. https://doi.org/10.1016/B978-1-4831-6743-5.50013-7

[93] Stubbe, M. and Gimsa, J. (2015) Maxwell's Mixing Equation Revisited: Characteristic Impedance Equations for Ellipsoidal Cells. Biophysical Journal, 109, 194-208. https://doi.org/10.1016/j.bpj.2015.06.021

[94] Papp, E., Vancsik, T., Kiss, E. and Szasz, O. (2017) Energy Absorption by the Membrane Rafts in the Modulated Electro-Hyperthermia (mEHT). Open Journal of Biophysics, 7, 216-229. https://doi.org/10.4236/ojbiphy.2017.74016

[95] Vincze, Gy., Szigeti, Gy. andocs, G. and Szasz, A. (2015) Nanoheating without Artificial Nanoparticles. Biology and Medicine, 7, 249.

[96] Megyesshazi, N. (2015) Studies on Modulated Electrohyperthermia Induced Tumor Cell Death in a Colorectal Carcinoma Model. Ph.D. Theses, Pathological Sciences Doctoral School, Semmelweis University, Budapest.

[97] Waldhauer, I. and Steinle, A. (2008) NK Cells and Cancer Immunosurveillance. Oncogene, 27, 5932-5943. https://doi.org/10.1038/onc.2008.267

[98] Zamai, L., Ponti, C., Mirandola, P., et al. (2007) NK Cells and Cancer. The Journal of Immunology, 178, 4011-4016. https://doi.org/10.4049/jimmunol.178.7.4011

[99] Hu, W., Wang, G., Huang, D., et al. (2019) Cancer Immunotherapy Based on Natural Cell Killer Cells: Current Progress and New Opportunities. Frontiers in Immunology, 10, Article No. 1205. https://doi.org/10.3389/fimmu.2019.01205

[100] Bassani, B., Baci, D. and Gallazzi, M. (2019) Natural Killer Cells as Key Players of Tumor Progression and Angiogenesis: Old and Novel Tools to Divert Their Pro-Tumor Activities into Potent Anti-Tumor Effects. Cancers, 11, 461. https://doi.org/10.3390/cancers11040461

[101] Betten, A., Dahlgren, C., Mellqvist, U.H., et al. (2004) Oxygen Radical-Induced Natural Killer Cell Dysfunction: Role of Myeloperosicase and Regulation by Serotonin. Journal of Leukocyte Biology, 75, 1111-1115. https://doi.org/10.1189/jlb.1103595

[102] Rosado, M.M., Simko, M., Mattsson, M.O. and Pioli, C. (2018) Immune-Modulating Perspectives for Low Frequency Electromagnetic Fields in Innate Immunity. Frontiers in Public Health, 6, Article No. 85. https://doi.org/10.3389/fpubh.2018.00085

[103] Reindl, L.M., Albinger, N., Bexte, T., et al. (2020) Immunotherapy with NK Cells: Recent Developments in Gene Modification Open Up New Avenues. OncoImmunology, 9, Article ID: 1777651. https://doi.org/10.1080/2162402X.2020.1777651

[104] Vancsik, T., Mathe, D., Horvath, I., et al. (2021) Modulated Electro-Hyperthermia Facilitates NK-Cell Infiltration and Growth Arrest of Human A2058 Melanoma in a Xenograft Model. Frontiers in Oncology, 11, Article ID: 590764. https://doi.org/10.3389/fonc.2021.590764

[105] Damele, L., Ottonello, S., Mingari, M.C., Pietra, G. and Vitale, C. (2020) Targeted Therapies: Friends or Foes for Patient's NK Cell-Mediated Tumor Immune-Surveillance? Cancers, 12, 774. https://doi.org/10.3390/cancers12040774

[106] Meggyeshazi, N. andocs, G., Balogh, L., Balla, P., Kiszner, G., Teleki, I., Jeney, A. and Krenacs, T. (2014) DNA Fragmentation and Caspase-Independent Programmed Cell Death by Modulated Electrohyperthermia. Strahlentherapie und Onkologie, 190, 815-822. https://doi.org/10.1007/s00066-014-0617-1

[107] Yang, K.L., Huang, C.C., Chi, M.S., Chiang, H.C., Wang, Y.S. andocs, G., et al. (2016) In Vitro Comparison of Conventional Hyperthermia and Modulated Electro-Hyperthermia. Oncotarget, 7, 84082-84092. 
https://doi.org/10.18632/oncotarget.11444

[108] Andocs, G., Meggyeshazi, N., Balogh, L., Spisak, S., Maros, M.E., Balla, P., Kiszner, G., Teleki, I., Kovago, Cs. and Krenacs, T. (2014) Upregulation of Heat Shock Proteins and the Promotion of Damage-Associated Molecular Pattern Signals in a Colorectal Cancer Model by Modulated Electrohyperthermia. Cell Stress and Chaperones, 20, 37-46. https://doi.org/10.1007/s12192-014-0523-6

[109] Jeon, T.W., Yang, H., Lee, C.G., et al. (2016) Electro-Hyperthermia Up-Regulates Tumour Suppressor Septin 4 to Induce Apoptotic Cell Death in Hepatocellular Carcinoma. International Journal of Hyperthermia, 7, 1-9. https://doi.org/10.1080/02656736.2016.1186290

[110] Vancsik, T., Kovago, Cs., Kiss, E., et al. (2018) Modulated Electro-Hyperthermia Induced Loco-Regional and Systemic Tumor Destruction in Colorectal Cancer Allografts. Journal of Cancer, 9, 41-53. https://doi.org/10.7150/jca.21520

[111] Szasz, A. (2019) Immune-Effects with Local Hyperthermia. Oncothermia Journal, 26, 139-148.

[112] Qin, W., Akutsu, Y. andocs, G., et al. (2014) Modulated Electro-Hyperthermia Enhances Dendritic Cell Therapy through an Abscopal Effect in Mice. Oncology Reports, 32, 2373-2379. https://doi.org/10.3892/or.2014.3500

[113] Tsang, Y.W., Huang, C.C., Yang, K.L., et al. (2015) Improving Immunological Tumor Microenvironment Using Electro-Hyperthermia Followed by Dendritic Cell Immunotherapy. BMC Cancer, 15, Article No. 708.

https://doi.org/10.1186/s12885-015-1690-2

[114] Wust, P., Kortum, B., Strauss, U., Nadobny, J., Zschaeck, S., Beck, M., et al. (2020) Nonthermal Effects of Radiofrequency Electromagnetic Fields. Scientific Reports, 10, Article No. 13488. https://doi.org/10.1038/s41598-020-69561-3

[115] Wust, P., Ghadjar, P., Nadobny, J., et al. (2019) Physical Analysis of TemperatureDependent Effects of Amplitude-Modulated Electromagnetic Hyperthermia. International Journal of Hygiene and Environmental Health, 36, 1246-1254. https://doi.org/10.1080/02656736.2019.1692376

[116] Wust, P., Nadobny, J., Zschaeck, S. and Ghadjar, P. (2020) Ch. 16. Physics of Hyperthermia-Is Physics Really against Us? In: Szasz, A., Ed., Challenges and Solutions of Oncological Hyperthermia, Cambridge Scholars Publishing, Newcastle upon Tyne District, 346-376.

[117] Szasz, A. (2019) Thermal and Nonthermal Effects of Radiofrequency on Living State and Applications as an Adjuvant with Radiation Therapy. Journal of Radiation and Cancer Research, 10, 1-17. https://doi.org/10.4103/jrcr.jrcr_25_18

[118] West, B.J. (1990) Fractal Physiology and Chaos in Medicine. World Scientific, Singapore, London. https://doi.org/10.1142/1025

[119] Goldberger, A.L., Amaral, L.A., Hausdorff, J.M., et al. (2002) Fractal Dynamics in Physiology: Alterations with Disease and Aging. PNAS Colloquium, 99, 2466-2472. https://doi.org/10.1073/pnas.012579499

[120] Stehlik, M., Hermann, P. and Nicolis, O. (2016) Fractal Based Cancer Modelling. REVSTAT-Statistical Journal, 14, 139-155.

[121] Deisboeck, T.S., Guiot, C., Delsanto, P.P., et al. (2006) Does Cancer Growth Depend on Surface Extension? Medical Hypotheses, 67, 1338-1341.

https://doi.org/10.1016/j.mehy.2006.05.029

[122] Stehlik, M., Wartner, F. and Minarova, M. (2013) Fractal Analysis for Cancer Research: Case Study and Simulation of Fractals. Pliska Studia Mathematica Bulgarica, 
22, 195-206.

[123] Waliszewski, P., Molski, M. and Konarski, J. (2011) Self-Similarity, Collectivity, and Evolution of Fractal Dynamics during Retinoid-Induced Differentiation of Cancer Cell Population. Fractals, 7, 139-149. https://doi.org/10.1142/S0218348X99000165

[124] Baish, J.W. and Jain, R.K. (2000) Fractals and Cancer. Cancer Research, 60, 3683-3688.

[125] Liu, S., Wang, Y., Xu, K., Wang, Z., Fan, X., Zhang, C., Li, S., Qiu, X. and Jiang, T. (2017) Relationship between Necrotic Patterns in Glioblastoma and Patient Survival: Fractal Dimension and Lacunarity Analyses Using Magnetic Resonance Imaging. Scientific Reports, 7, Article No. 8302. https://doi.org/10.1038/s41598-017-08862-6

[126] Szasz, A. (2021) The Capacitive Coupling Modalities for Oncological Hyperthermia. Open Journal of Biophysics, 11, 252-313. https://doi.org/10.4236/ojbiphy.2021.113010

[127] Zbilut, J.P. and Marwan, N. (2008) The Wiener-Khinchin Theorem and Recurrence Quantification. Physics Letters A, 372, 6622-6626.

https://doi.org/10.1016/j.physleta.2008.09.027

[128] Petrova, Y.I., Schecterson, L. and Gumbiner, B.M. (2016) Roles for E-cadherin Cell Surface Regulation in Cancer. Molecular Biology of the Cell, 27, 3233-3244. https://doi.org/10.1091/mbc.E16-01-0058

[129] Beavon, I.R. (2000) The E-cadherin-catenin Complex in Tumour Metastasis: Structure, Function and Regulation. European Journal of Cancer, 36, 1607-1620. https://doi.org/10.1016/S0959-8049(00)00158-1

[130] Pećina-Šlaus, N. (2003) Tumor Suppressor Gene E-cadherin and Its Role in Normal and Malignant Cells. Cancer Cell International, 3, 17. https://doi.org/10.1186/1475-2867-3-17

[131] Cavallaro, U., Schaffhauser, B. and Christofori, G. (2002) Cadherins and the Tumour Progression: Is It All in a Switch? Cancer Letters, 176, 123-128. https://doi.org/10.1016/S0304-3835(01)00759-5

[132] Szentgyorgyi, A. (1968) Bioelectronics: A Study on Cellular Regulations, Defence and Cancer. Academic Press, New York, London.

[133] Lowenstein, W.R. and Kanno, Y. (1967) Intercellular Communication and Tissue Growth, I. Cancerous Growth. The Journal of Cell Biology, 33, 225-234. https://doi.org/10.1083/jcb.33.2.225

[134] Lowenstein, W.R. and Penn, R.D. (1967) Intercellular Communication and Tissue Growth, II. Tissue Regeneration. The Journal of Cell Biology, 33, 235-242. https://doi.org/10.1083/jcb.33.2.235

[135] Alimperti, S. and Andreadis, S.T. (2015) CDH2 and CDH11 Act as Regulators of Stem Cell Fate Decisions. Stem Cell Research, 14, 270-282. https://doi.org/10.1016/j.scr.2015.02.002

[136] Szentgyorgyi, A. (1965) Cell Division and Cancer. Science, 149, 34-37. https://doi.org/10.1126/science.149.3679.34

[137] Lugano, R., Ramachandran, M. and Dimberg, A. (2020) Tumor Angiogénesis: Causes, Consequences, Challenges and Opportunities. Cellular and Molecular Life Sciences, 77, 1745-1770. https://doi.org/10.1007/s00018-019-03351-7

[138] Szasz, O. and Szasz, A. (2018) Modulated Electro-Hyperthermia, (mEHT) from LAB to Clinic. Oncothermia Journal, 23, 24-61.

[139] Ritossa, F. (1962) A New Puffing Pattern Induced by Temperature Shock and DNP in Drosophila. Experimental, 18, 571-573. https://doi.org/10.1007/BF02172188 
[140] Csermely, P. (1998) Stress of Life from Molecules to Man. Annals of the New York Academy of Sciences, 851, 547. https://doi.org/10.1111/j.1749-6632.1998.tb08965.x

[141] Soti, C. and Csermely, P. (2007) Protein Stress and Stress Proteins: Implications in Aging and Disease. Journal of Biosciences, 32, 511-515.

https://doi.org/10.1007/s12038-007-0050-Z

[142] Vega, V.L., Rodriguez, Silva, M., Frey, T., Gehrmann, M., Diaz, J.C., et al. (2008) Hsp70 Translocates into the Plasma Membrane after Stress and Is Released into the Extracellular Environment in a Membrane-Associated form That Activates Macrophages. The Journal of Immunology, 180, 4299-4307. https://doi.org/10.4049/jimmunol.180.6.4299

[143] Juhasz, K., Lipp, A.M., Nimmervoll, B., Sonnleitner, A., et al. (2013) The Complex Function of Hsp70 in Metastatic Cancer. Cancers, 6, 42-66.

https://doi.org/10.3390/cancers6010042

[144] Ohtsuka, K., Kawashima, D. and Asai, M. (2007) Dual Functions of Heat Shock Proteins: Molecular Chaperones Inside of Cells and Danger Signals Outside of Cells. Thermal Medicine, 23, 11-22. https://doi.org/10.3191/thermalmedicine.23.11

[145] Soti, Cs., Nagy, E., Giricz, Z., Vigh, L., Csermely, P. and Ferdinandy, P. (2005) Heat Shock Proteins as Emerging Therapeutic Targets. British Journal of Pharmacology, 146, 679-780. https://doi.org/10.1038/sj.bjp.0706396

[146] Torok, Z.S., Crul, T., Maresca, B., Schutz, G.J., Viana, F., et al. (2014) Plasma Membranes as Heat Stress Sensors: From Lipid-Controlled Molecular Switches to Therapeutic Applications. Biochimica et Biophysica Acta, 1838, 1594-1618. https://doi.org/10.1016/j.bbamem.2013.12.015

[147] Shevtsov, M., Balogi, Z.S., Khachatryan, W., Gao, H., Vigh, L. and Multhof, F.G. (2020) Membrane-Associated Heat Shock Proteins in Oncology: From Basic Research to New Theranostic Targets. Cells, 9, 1263. https://doi.org/10.3390/cells9051263

[148] Andocs, G., Rehman, M.U., Zhao, Q.L., Papp, E., Kondo, T. and Szasz, A. (2015) Nanoheating without Artificial Nanoparticles Part II. Experimental Support of the Nanoheating Concept of the Modulated Electro-Hyperthermia Method, Using U937 Cell Suspension Model. Biology and Medicine, 7, 1-9. https://doi.org/10.4172/0974-8369.1000247

[149] Danics, L., Schvarcz, Cs., Viana, P., et al. (2020) Exhaustion of Protective Heat Shock Response Induces Significant Tumor Damage by Apoptosis after Modulated Electro-Hyperthermia Treatment of Triple Negative Breast Cancer Isografts in Mice. Cancers, 12, 2581. https://doi.org/10.3390/cancers12092581

[150] Wang, X.Y., Li, Y., Yang, G. and Subjeck, J.R. (2005) Current Ideas about Applications of Heat Shock Proteins in Vaccine Design and Immunotherapy. International Journal of Hyperthermia, 21, 717-722. https://doi.org/10.1080/02656730500226407

[151] Calderwood, S.K., Mambula, S.S. and Gray Jr., P.J. (2007) Extracellular Heat Shock Proteins in Cell Signalling and Immunity. Annals of the New York Academy of Sciences, 1113, 28-39. https://doi.org/10.1196/annals.1391.019

[152] Pederson, T. (2003) Historical Review: An Energy Reservoir for Mitosis, and Its Productive Wake. Trends in Biochemical Sciences, 28, 125-129. https://doi.org/10.1016/S0968-0004(03)00030-6

[153] Warburg, O. (1996) Oxygen, The Creator of Differentiation, Biochemical Energetics. Academic Press, New York.

[154] Szentgyorgyi, A. (1998) Electronic Biology and Cancer. Marcel Dekker, New York. 
[155] Sengupta, A., Gupta, S., Sharda, A., et al. (2021) Effect of Low Frequency Electrical Current on the Biophysical and Molecular Properties of Cancer Cells. International Journal of Cancer and Clinical Research, 8, 145. https://doi.org/10.23937/2378-3419/1410145

[156] Lanouette, W. and Silard, B. (1992) Genius in the Shadows. Macmillan Publishing Co., New York.

[157] Meng, X. and Riordan, N.H. (2006) Cancer Is a Functional Repair Tissue. Medical Hypotheses, 66, 486-490. https://doi.org/10.1016/j.mehy.2005.09.041

[158] McCarthy-Morrogh, L. and Martin, P. (2020) The Hallmarks of Cancer Are Also Hallmarks of Wound Healing. Science Signaling, 13, eaay8690.

https://doi.org/10.1126/scisignal.aay8690

[159] Deyell, M., Garris C.S. and Laughney, A.M. (2021) Cancer Metastasis as a Non-Healing Wound. British Journal of Cancer, 124, 1491-1502. https://doi.org/10.1038/s41416-021-01309-w

[160] Sundaram, G.M., Quah, S. and Sampath, P. (2018) Cancer: The Dark Side of Wound Healing. The FEBS Journal, 285, 4516-4534.

https://doi.org/10.1111/febs.14586

[161] Shin, B.J. and Ching, S.S. (2003) A Case of Limbal Stem Cell Deficiency in a Patient with Chronic Mucocutaneous Candiddiasis. Investigative Ophthalmology \& Visual Science, 44, 1359.

[162] Houghton, J., Stoicov, C., Nomura, S., et al. (2004) Gastric Cancer Originating from Bone Marrow-Derived Cells. Science, 306, 1568-1571.

https://doi.org/10.1126/science.1099513

[163] Ouahes, N., Phillips, T.J. and Park, H.Y. (1998) Expression of c-fos and c-Ha-ras Protooncogenes Is Induced in Human Chronic Wounds. Dermatologic Surgery, 24, 1354-1357. https://doi.org/10.1111/j.1524-4725.1998.tb00014.x

[164] Huang, S., Trujillo, J.M. and Chakrabarty, S. (1992) Proliferation of Human Colon Cancer Cells: Role of Epidermal Growth Factor and Transforming Growth Factor. International Journal of Cancer, 52, 978-986. https://doi.org/10.1002/ijc.2910520625

[165] Dahiya, R., Lee, C., Haughney, P.C., et al. (1996) Differential Gene Expression of Transforming Growth Factors Alpha and Beta, Epidermal Growth Factor, Keratinocyte Growth Factor, and Their Receptors in Fetal and Adult Human Prostatic Tissues and Cancer Cell Lines. Urology, 48, 963-970. https://doi.org/10.1016/S0090-4295(96)00376-7

[166] Mizuno, K., Sone, S., Orino, E., et al. (1994) Autonomous Expressions of Cytokine Genes by Human Lung Cancer Cells and Their Paracrine Regulation. Japanese Journal of Cancer and Oncology Research, 85, 179-186. https://doi.org/10.1111/j.1349-7006.1994.tb02080.x

[167] Zhang, H., Vutskits, L., Pepper, M.S., et al. (2003) VEGF Is a Chemoattractant for FGF-2-Stimulated Neural Progenitors. Journal of Cell Biology, 163, 1375-1384. https://doi.org/10.1083/jcb.200308040

[168] Cicuttini, F.M., Begley, C.G. and Boyd, A.W. (1992) The Effect of Recombinant Stem Cell Factor (SCF) on Purified CD34-Positive Human Umbilical Cord Blood Progenitor Cells. Growth Factors, 6, 31-39.

https://doi.org/10.3109/08977199209008869

[169] Lovelady, D.C., Richmond, T.C., Maggi, A.N., Lo, C.M. and Rabson, D.A. (2007) Distinguishing Cancerous from Non-Cancerous Cells through Analysis of Electrical Noise. Physical Review E, 76, Article ID: 041908. 
https://doi.org/10.1103/PhysRevE.76.041908

[170] Lovelady, D.C., Friedman, J., Patel, S., et al. (2009) Detecting Effects of Low Levels of Cytochalasin B in 3T3 Fibroblast Cultures by Analysis of Electrical Noise Obtained from Cellular Micromotion. Biosensors and Bioelectronics, 24, 2250-2254. https://doi.org/10.1016/j.bios.2008.09.033

[171] Lineweaver, C.H., Davies, P.C.W. and Vincent, M.D. (2014) Targeting Cancer's Weaknesses (Not Its Strengths): Therapeutic Strategies Suggested by the Atavistic Model. Bioessays, 36, 827-835. https://doi.org/10.1002/bies.201400070

[172] Jezequel, P. and Campone, M. (2018) Comment on "How the Evolution of Multicellularity Set the Stage for Cancer”. British Journal of Cancer, 119, 133-134.

https://doi.org/10.1038/s41416-018-0091-0

[173] Andocs, G., Szasz, O. and Szasz, A. (2009) Oncothermia Treatment of Cancer: From the Laboratory to Clinic. Electromagnetic Biology and Medicine, 28, 148-165. https://doi.org/10.1080/15368370902724633

[174] Wust, P., Ghadjar, P., Nadobny, J. and Beck, M. (2019) Physical Potentials of Radiofrequency Hyperthermia with Amplitude Modulation. Oncothermia Journal, 26, 128-137.

[175] Vincze, Gy. and Szasz, A. (2018) Similarities of Modulation by Temperature and by Electric Field. Ojbiphy, 8, 95-103. https://doi.org/10.4236/ojbiphy.2018.83008

[176] Andocs, G., Renner, H., Balogh, L., Fonyad, L., Jakab, C. and Szasz, A. (2009) Strong Synergy of Heat and Modulated Electro-Magnetic Field in Tumor Cell Killing, Study of HT29 Xenograft Tumors in a Nude Mice Model. Strahlentherapie und Onkologie, 185, 120-126. https://doi.org/10.1007/s00066-009-1903-1

[177] Nagy, G., Meggyeshazi, N. and Szasz, O. (2013) Deep Temperature Measurements in Oncothermia Processes. Conference Papers in Medicine, 2013, Article ID: 685264. https://doi.org/10.1155/2013/685264

[178] Hossain, M.T., Prasad, B., Park, K.S., et al. (2016) Simulation and Experimental Evaluation of Selective Heating Characteristics of 13, $56 \mathrm{MHz}$ Radiofrequency Hyperthermia in Phantom Models. International Journal of Precision Engineering and Manufacturing, 17, 253-256. https://doi.org/10.1007/s12541-016-0033-9

[179] Orczy-Timko, B. (2020) Ch. 18. Phantom Measurements with the EHY-2030 Device. In: Szasz, A., Ed., Challenges and Solutions of Oncological Hyperthermia, Cambridge Scholars Publishing, Newcastle upon Tyne District, 416-428.

[180] Szasz, O. and Szasz, A. (2021) Approaching Complexity: Hyperthermia Dose and Its Possible Measurement in Oncology. Ojbiphy, 11, 68-132.

https://doi.org/10.4236/ojbiphy.2021.111002

[181] Szasz, A. and Vincze, Gy. (2006) Dose Concept of Oncological Hyperthermia: HeatEquation Considering the Cell Destruction. Journal of Cancer Research and Therapeutics, 2, 171-181. https://doi.org/10.4103/0973-1482.29827

[182] Lee, S.Y., Szigeti, G.P. and Szasz, A.M. (2019) Oncological Hyperthermia: The Correct Dosing in Clinical Applications. International Journal of Oncology, 54, 627-643. https://doi.org/10.3892/ijo.2018.4645

[183] Szasz, A., Vincze, Gy., Szasz, O. and Szasz, N. (2003) An Energy Analysis of Extracellular Hyperthermia. Magneto- and Electro-Biology, 22, 103-115.

https://doi.org/10.1081/JBC-120024620

[184] Vincze, Gy. and Szasz, A. (2015) Effect of Cellular Membrane Resistivity Inhomogeneity on the Thermal Noise-Limit. Journal of Advances in Physics, 11, 3170-3183.

https://doi.org/10.24297/jap.v11i3.6859 
[185] Vincze, Gy. and Szasz, A. (2015) Reorganization of Actin Filaments and Microtubules by Outside Electric Field. Journal of Advances in Biology, 8, 1514-1518.

[186] Lee, S.Y., Fiorentini, G., Szasz, A.M., Szigeti, Gy., Szasz, A. and Minnaar, C.A. (2020) Quo Vadis Oncological Hyperthermia (2020)? Frontiers in Oncology, 10, Article No. 1690. https://doi.org/10.3389/fonc.2020.01690

[187] Szasz, O. and Szasz, A. (2014) Oncothermia-Nano-Heating Paradigm. Journal of Cancer Science and Therapy, 6, 4. https://doi.org/10.4172/1948-5956.1000259

[188] Szasz, A. (2013) Chapter 4. Electromagnetic Effects in Nanoscale Range. In: Shimizu, T. and Kondo, T., Eds., Cellular Response to Physical Stress and Therapeutic Applications, Nova Science Publishers, Hauppauge, 55-81.

[189] Andocs, G., Rehman, M.U., Zhao, Q.L., Tabuchi, Y., Kanamori, M. and Kondo, T. (2016) Comparison of Biological Effects of Modulated Electro-Hyperthermia and Conventional Heat Treatment in Human Lymphoma U937 Cell. Cell Death Discovery, 2, 16039. https://doi.org/10.1038/cddiscovery.2016.39

[190] Szasz, A. (2020) Towards the Immunogenic Hyperthermic Action: Modulated Electro-Hyperthermia. Clinical Oncology and Research, Science Repository, 3, 5-6. https://doi.org/10.31487/j.COR.2020.09.07

[191] Kim, J.K., Prasad, B. and Kim, S. (2017) Temperature Mapping and Thermal Dose Calculation in Combined Radiation Therapy and 13.56 MHz Radiofrequency Hyperthermia for Tumor Treatment. Proceedings SPIE 10047, Optical Methods for Tumor Treatment and Detection: Mechanisms and Techniques in Photodynamic Therapy XXVI, Volume 10047, Article ID: 1004718.

https://doi.org/10.1117/12.2253163

[192] Prasad, B., Kim, S., Cho, W., et al. (2019) Quantitative Estimation of the Equivalent Radiation Dose Escalation Using Radiofrequency Hyperthermia in Mouse Xenograft Models of Human Lung Cancer. Scientific Reports, 9, Article No. 3942. https://doi.org/10.1038/s41598-019-40595-6

[193] Forika, G., Balogh, A., Vancsik, T., Zalatnai, A., et al. (2020) Modulated ElectroHyperthermia Resolves Radioresistance of Panc1 Pancreas Adenocarcinoma and Promotes DNA Damage and Apoptosis in Vitro. International Journal of Molecular Sciences, 21, 5100. https://doi.org/10.3390/ijms21145100

[194] Vancsik, T., Forika, G., Balogh, A., et al. (2019) Modulated Electro-Hyperthermia Induced p53 Driven Apoptosis and Cell Cycle Arrest Additively Support Doxorubicin Chemotherapy of Colorectal Cancer in Vitro. Cancer Medicine, 8, 4292-4303. https://doi.org/10.1002/cam4.2330

[195] Tsang, Y.W., Chi, K.H., Huang, C.C., et al. (2019) Modulated Electro-Hyperthermia-Enhanced Liposomal Drug Uptake by Cancer Cells. International Journal of Nanomedicine, 14, 1269-1579. https://doi.org/10.2147/IJN.S188791

[196] Krenacs, T., Meggyeshazi, N., Forika, G., et al. (2020) Modulated Electro-Hyperthermia-Induced Tumor Damage Mechanisms Revealed in Cancer Models. International Journal of Molecular Sciences, 21, 6270.

https://doi.org/10.3390/ijms21176270

[197] Wismeth, C., Dudel, C., Pascher, C., et al. (2010) Transcranial Electro-Hyperthermia Combined with Alkylating Chemotherapy in Patients with Relapsed High-Grade Gliomas-Phase I Clinical Results. Journal of Neuro-Oncology, 98, 395-405. https://doi.org/10.1007/s11060-009-0093-0

[198] Sahinbas, H., Groenemeyer, D.H.W., Boecher, E. and Szasz, A. (2007) Retrospective Clinical Study of Adjuvant Electro-Hyperthermia Treatment for Advanced BrainGliomas. Deutsche Zeitschriftfuer Onkologie, 39, 154-160. 
https://doi.org/10.1055/s-2007-986020

[199] Fiorentini, G., Sarti, D., Milandri, C., et al. (2018) Modulated Electrohyperthermia in Integrative Cancer Treatment for Relapsed Malignant Glioblastoma and Astrocytoma: Retrospective Multicenter Controlled Study. Integrative Cancer Therapies, 18, 1-11. https://doi.org/10.1177/1534735418812691

[200] Fiorentini, G., Sarti, D., Casadei, V., et al. (2020) Ch. 6. Modulated Electro-Hyperthermia for the Treatment of Relapsed Brain Gliomas. In: Szasz, A., Ed., Challenges and Solutions of Oncological Hyperthermia, Cambridge Scholars Publishing, Newcastle upon Tyne District, 110-125.

[201] Ou, J., Zhu, X., Lu, Y., et al. (2017) The Safety and Pharmacokinetics of High Dose Intravenous Ascorbic Acid Synergy with Modulated Electrohyperthermia in Chinese Patients with Stage III-IV Non-Small Cell Lung Cancer. European Journal of Pharmaceutical Sciences, 109, 412-418. https://doi.org/10.1016/j.ejps.2017.08.011

[202] Ou, J., Zhu, X., Chen, P., et al. (2020) A Randomized Phase II Trial of Best Supportive Care with or without Hyperthermia and Vitamin C for Heavily Pretreated, Advanced, Refractory Non-Small-Cell Lung Cancer. Journal of Advanced Research, 24, 175-182. https://doi.org/10.1016/j.jare.2020.03.004

[203] Roussakow, S. (2017) Clinical and Economic Evaluation of Modulated Electrohyperthermia Concurrent to Dose-Dense Temozolomide 21/28 Days Regimen in the Treatment of Recurrent Glioblastoma: A Retrospective Analysis of a Two-Centre German Cohort Trial with Systematic Comparison and Effect-to-Treatment Analysis. BMJ Open, 7, e017387. https://doi.org/10.1136/bmjopen-2017-017387

[204] Roussakow, S.V. (2016) Pharmacoeconomic Study of Oncothermia (Modulated Electro-Hyperthermia) in the Treatment of Lung Cancer. Oncothermia Journal, 18, 116-138.

[205] Ranieri, G., Laface, C., Laforgia, M., et al. (2020) Bevacizumab plus FOLFOX-4 Combined with Deep Electro-Hyperthermia as First-Line Therapy in Metastatic Colon Cancer: A Pilot Study. Frontiers in Oncology, 10, Article ID: 590707. https://doi.org/10.3389/fonc.2020.590707

[206] Kim, S., Lee, J.H., Cha, J. and You, S.H. (2021) Beneficial Effects of Modulated Electro-Hyperthermia during Neoadjuvant Treatment for Locally Advanced Rectal Cancer. International Journal of Hyperthermia, 38, 144-151. https://doi.org/10.1080/02656736.2021.1877837

[207] Gadaleta-Caldarola, G., Infusino, S., Galise, I., et al. (2014) Sorafenib and Locoregional Deep Electro-Hyperthermia in Advanced Hepatocellular Carcinoma. A Phase II Study. Oncology Letters, 8, 1783-1787. https://doi.org/10.3892/ol.2014.2376

[208] Fiorentini, G., Sarti, D., Casadei, V., et al. (2019) Modulated Electro-Hyperthermia as Palliative Treatment for Pancreas Cancer: A Retrospective Observational Study on 106 Patients. Integrative Cancer Therapies, 18, 1-8.

https://doi.org/10.1177/1534735419878505

[209] Volovat, C., Volovat, S.R., Scripcaru, V., et al. (2014) Second-Line Chemotherapy with Gemcitabine and Oxaliplatin in Combination with Loco-Regional Hyperthermia (EHY-2000) in Patients with Refractory Metastatic Pancreatic Cancer-Preliminary Results of a Prospective Trial. Romanian Reports in Physics, 66, 166-174.

[210] Yoo, H.J., Lim, M.C., Seo, S.S., et al. (2019) Phase I/II Clinical Trial of Modulated Electro-Hyperthermia Treatment in Patients with Relapsed, Refractory or Progressive Heavily Treated Ovarian Cancer. Japanese Journal of Clinical Oncology, 49, 832-838. https://doi.org/10.1093/jico/hyz071

[211] Lee, S.Y., Lee, N.R., Cho, D.H., et al. (2017) Treatment Outcome Analysis of Che- 
motherapy Combined with Modulated Electro-Hyperthermia Compared with Chemotherapy Alone for Recurrent Cervical Cancer, Following Irradiation. Oncology Letters, 14, 73-78. https://doi.org/10.3892/ol.2017.6117

[212] Minnaar, C.A., Kotzen, J.A., Ayeni, O.A., et al. (2019) The Effect of Modulated Electro-Hyperthermia on Local Disease Control in HIV-Positive and -Negative Cervical Cancer Women in South Africa: Early Results from a Phase III Randomized Controlled Trial. PLOS ONE, 14, e0217894.

https://www.ncbi.nlm.nih.gov/pmc/articles/PMC6584021

https://doi.org/10.1371/journal.pone.0217894

[213] Minnaar, C.A., Kotzen, J.A., Naidoo, T., et al. (2020) Analysis of the Effects of mEHT on the Treatment-Related Toxicity and Quality of Life of HIV-Positive Cervical Cancer Patients. International Journal of Hyperthermia, 37, 263-272. https://doi.org/10.1080/02656736.2020.1737253

[214] Jeung, T.S., Ma, S.Y., Choi, J., et al. (2015) Results of Oncothermia Combined with Operation, Chemotherapy and Radiation Therapy for Primary, Recurrent and Metastatic Sarcoma. Case Reports in Clinical Medicine, 4, 157-168. https://doi.org/10.4236/crcm.2015.45033

[215] Volovat, C., Volovat, S.R., Scripcaru, V., et al. (2014) The Results of Combination of Ifosfamid and Locoregional Hyperthermia (EHY 2000) in Patients with Advanced Abdominal Soft-Tissue Sarcoma after Relapse of First Line Chemotherapy. Romanian Reports in Physics, 66, 175-181.

[216] Van, Gool, S.W., Makalowski, J., Feyen, O., Prix, L., Schirrmacher, V. and Stuecker, W. (2018) The Induction of Immunogenic Cell Death (ICD) during Maintenance Chemotherapy and Subsequent Multimodal Immunotherapy for Glioblastoma (GBM). Austin Oncology Case Reports, 3, 1010.

[217] Chi, M.S., Mehta, M.P., Yang, K.L., et al. (2020) Putative Abscopal Effect in Three Patients Treated by Combined Radiotherapy and Modulated Electrohyperthermia. Frontiers in Oncology, 10, Article No. 254. https://doi.org/10.3389/fonc.2020.00254

[218] Minnaar, C.A., Kotzen, J.A., Ayeni, O.A., et al. (2020) Potentiation of the Abscopal Effect by Modulated Electro-Hyperthermia in Locally Advanced Cervical Cancer Patients. Frontiers in Oncology, 10, Article No. 376. https://doi.org/10.3389/fonc.2020.00376

[219] Chi, K.H. (2020) Ch. 12. Tumour-Directed Immunotherapy: Clinical Results of Radiotherapy with Modulated Electro-Hyperthermia. In: Szasz, A., Ed., Challenges and Solutions of Oncological Hyperthermia, Cambridge Scholars Publishing, Newcastle upon Tyne District, 206-226.

https://www.cambridgescholars.com/challenges-and-solutions-of-oncological-hype rthermia

[220] Van, Gool, S.W., Makalowski, J., Domogalla, M.P., et al. (2020) Ch. 7. Personalised Medicine in Glioblastoma Multiforme. In: Szasz, A., Ed., Challenges and Solutions of Oncological Hyperthermia, Cambridge Scholars Publishing, Newcastle upon Tyne District, 126-158.

[221] Pang, C.L.K., Zhang, X., Wang, Z., et al. (2017) Local Modulated Electro-Hyperthermia in Combination with Traditional Chinese Medicine vs. Intraperitoneal Chemoinfusion for the Treatment of Peritoneal Carcinomatosis with Malignant Ascites: A Phase II Randomized Trial. Molecular and Clinical Oncology, 6, 723-732. https://doi.org/10.3892/mco.2017.1221

[222] Szasz, A.M., Minnaar, C.A., Szentmartoni, Gy., et al. (2019) Review of the Clinical Evidences of Modulated Electro-Hyperthermia (mEHT) Method: An Update for the 
Practicing Oncologist. Frontiers in Oncology, 9, Article No. 1012. https://doi.org/10.3389/fonc.2019.01012

[223] Szasz, A.M., Arkosy, P., Arrojo, E.E., et al. (2020) Ch. 2. Guidelines for Local Hyperthermia Treatment in Oncology. In: Szasz, A., Ed., Challenges and Solutions of Oncological Hyperthermia, Cambridge Scholars Publishing, Newcastle upon Tyne District, 32-71.

[224] Van, Gool, S.W., Makalowski, J., Fiore, S., et al. (2021) Randomized Controlled Immunotherapy Clinical Trials for GBM Challenged. Cancers, 13, 32. https://doi.org/10.3390/cancers13010032

[225] Szasz, A., Szasz, N. and Szasz, O. (2010) Oncothermia-Principles and Practices. Springer Science, Heidelberg. https://doi.org/10.1007/978-90-481-9498-8

[226] Parmar, G., Rurak, E., Elderfield, M., et al. (2020) Ch. 13. 8-Year Observational Study on Naturopathic Treatment with Modulated Electro-Hyperthermia (mEHT): A Single-Centre Experience. In: Szasz, A., Ed., Challenges and Solutions of Oncological Hyperthermia, Cambridge Scholars Publishing, Newcastle upon Tyne District, 227-266.

[227] Hager, E.D., Sahinbas, H., Groenemeyer, D.H., et al. (2008) Prospectivephase II Trial for Recurrent High-Grade Malignant Gliomas with Capacitive Coupled Low Radiofrequency (LRF) Deep Hyperthermia. ASCO, Journal of Clinical Oncology, Annual Meeting Proceedings (Post-Meeting Edition), 26, 2047. https://doi.org/10.1200/jco.2008.26.15_suppl.2047

[228] Renner, H. and Albrecht, I. (2007) Analyseder Überlebenszeiten von Patineten mit Pankreastumoren mit erfolgterkapazitativer Hyperthermiebehandlung, (Erstellt: Mr. Mirko Friedrich; May \& STM.

[229] Dani, A., Varkonyi, A., Magyar, T. and Szasz, A. (2008) Clinical Study for Advanced Pancreas Cancer Treated by Oncothermia. Forum Hyperthermie, 1, 13-20.

[230] Parmar, G. (2018) Naturopathic Anti-Tumoral Treatment \& 8 Year Survival Benefit Statistics: A Single-Centre Experience. 36th Conference of the International Clinical Hyperthermia Society, Budapest, 28-29 September 2018.

[231] SEER (Surveillance, Epidemiology, and End Result Program) Database. https://seer.cancer.gov/data

[232] Szasz, O. and Szasz, A. (2020) Parametrization of Survival Measures, Part I: Consequences of Self-Organizing. International Journal of Clinical Medicine, 11, 316-347. https://doi.org/10.4236/ijcm.2020.115031

[233] Szasz, O., Szasz, A.M., Szigeti, G.P. and Szasz, A. (2020) Chapter 2. Data Mining and Evaluation of Single Arm Clinical Studies. In: Yong, X., Ed., Recent Developments in Engineering Research, Vol. 3, GAN Publishing, London, 15-74.

[234] Szasz, A., Szigeti, G.P. and Szasz, A.M. (2020) Parametrization of Survival Measures, Part II: Single Arm Studies. International Journal of Clinical Medicine, 11, 348-373. https://doi.org/10.4236/ijcm.2020.115032

[235] Szasz, A., Szigeti, G.P. and Szasz, A.M. (2020) Parametrization of Survival Measures, Part III: Clinical Evidences in Single Arm Studies with Endpoint of Overall Survival. International Journal of Clinical Medicine, 11, 389-419.

https://doi.org/10.4236/ijcm.2020.116034 